\title{
A QUÍMICA MEDICINAL DE N-ACILIDRAZONAS: NOVOS COMPOSTOS-PROTÓTIPOS DE FÁRMACOS ANALGÉSICOS, ANTIINFLAMATÓRIOS E ANTI-TROMBÓTICOS
}

Eliezer J. Barreiro ${ }^{* 1}$, Carlos A. M. Fraga, Ana L. P. Miranda, Carlos R. Rodrigues

Faculdade de Farmácia ${ }^{2}$, Universidade Federal do Rio de Janeiro, Cidade Universitária, Ilha do Fundão, CP 68.006, 21944-190

Rio de Janeiro RJ

Recebido em 1/3/01; aceito em 13/6/01

\begin{abstract}
MEDICINAL CHEMISTRY OF N-ACYLHYDRAZONES: NOVEL LEAD-COMPOUNDS OF ANALGESIC, ANTIINFLAMMATORY AND ANTITHROMBOTIC DRUGS. In this article are described new bioactive $N$-acylhydrazone (NAH) derivatives, structurally designed as optimization of aryl hydrazones precursors planned by molecular hybridization of two 5lipoxigenase inhibitors, e.g. CBS-1108 and BW-755c. The analgesic, antiedematogenic and anti-platelet aggregating profile of several isosteric compounds was investigated by using classic pharmacological assays in vivo and ex-vivo, allowing to identify new potent peripheric analgesic lead, a new anti-inflammatory and an antithrombotic agent. During this study was discovered dozen of active NAH compounds clarifying the structure-activity relationship for this series of NAH derivatives, indicating the pharmacophore character of the $N$-acylhydrazone functionality.
\end{abstract}

Keywords: bioactive $N$-acylhydrazones derivatives; antiinflammatory, analgesic and antithrombotic properties; molecular hybridization and bioisosterism in drug design.

\section{INTRODUÇÃO}

A Química Medicinal estuda as razões moleculares da ação dos fármacos ${ }^{1}$ de maneira a descrever a relação entre a estrutura química e a atividade farmacológica, hierarquizando as diferentes contribuições funcionais. No contexto inverso, inclui-se o planejamento e o desenho estrutural de novas substâncias que possuam propriedades farmacoterapêuticas úteis, capazes de representarem novas entidades químicas, candidatas a protótipos de novos fármacos de uso seguro. Esta complexa tarefa envolve múltiplos fatores, responsáveis pela resposta terapêutica desejada e decorrentes da complexidade dos sistemas biológicos, abrangendo diversos conceitos de diferentes disciplinas, não podendo ser cumprida aleatoriamente. Heuristicamente para a identificação de um novo composto-protótipo ou uma nova entidade química que possa representar novo candidato a fármaco, elege-se o melhor alvo-farmacológico para aquela aplicação terapêutica e, em função do nível de conhecimento estrutural disponível sobre este receptor, identifica-se a melhor estratégia para a construção da arquitetura molecular do novo ligante desejado. Diversas estratégias modernas de desenho molecular de novos protótipos são conhecidas ${ }^{2}$, em função do mecanismo de ação pretendido, seja inibição enzimática, reversível ou não, ou agonismo/antagonismo, competitivo ou não, do receptor, que dependem do nível de conhecimento de sua topografia.

O conhecimento da topografia molecular tridimensional (3D) do receptor, especialmente do sítio de interação, permite o desenho de inibidores enzimáticos ou de antagonistas/agonistas de receptores, por processos de complementaridade molecular planejada, ${ }^{3}$ que podem, por sua vez, discriminar entre interações ou ligações covalentes ${ }^{4}$. Quando não se conhece a estrutura do biorreceptor-alvo, a estratégia mais empregada fundamenta-se na variação da similaridade molecular

\footnotetext{
1 eliezer@ufrj.br

${ }^{2}$ Laboratório de Avaliação e Síntese de Substâncias Bioativas (LASSBio, http://www.farmacia.ufrj.br/lassbio).
}

do agonista natural de forma a que se identifique um análogo ativo ${ }^{5}$, reflexo de suas propriedades farmacodinâmicas, que governam seu reconhecimento molecular pelo biorreceptor. Uma vez comprovada a atividade farmacológica desejada do novo análogo-ativo, por meio de protocolos farmacológicos in vivo, têm-se um novo composto-protótipo, candidato ao novo fármaco pretendido (Figura 1).

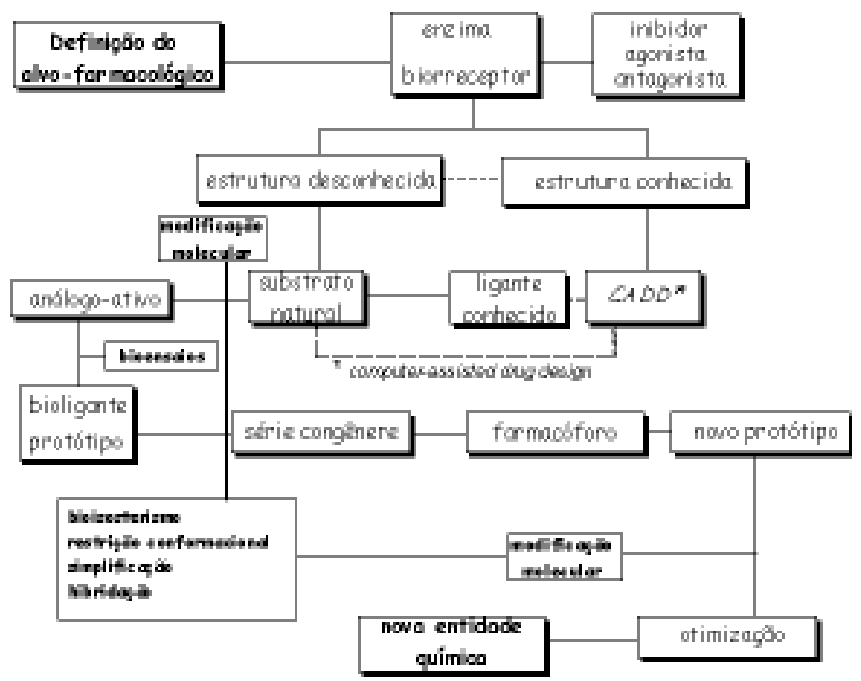

Figura 1. Seqüência heurística para a descoberta de novas entidades químicas.

O novo composto-protótipo, uma vez identificado, pode ter sua eficácia otimizada por modificações moleculares subseqüentes, planejadas de maneira a preservar ou aprimorar as propriedades farmacocinéticas identificadas nos ensaios in vivo. Para tanto, diferentes estratégias são possíveis como, por exemplo, o desenho de isósteros do análogo-ativo ${ }^{6}$ em que, novamente, o conhecimento dos grupos farmacofóricos do protótipo norteiam as modificações estruturais a serem introduzidas, de modo a preservá-los? ${ }^{7}$. Deve-se, ainda, levar em 
consideração as eventuais contribuições toxicofóricas de todas as subunidades estruturais envolvidas, particularmente ao nível do sistema microssomal hepático, onde predominam reações de oxidação que são essenciais à bioformação de diversas substâncias endógenas, como os hormônios esteróides, reguladores de funções fisiológicas vitais. ${ }^{8}$

Entre os processos úteis para a identificação de novos protótipos, candidatos a fármacos, a hibridação molecular ${ }^{9}$ de inibidores enzimáticos ou antagonistas de biorreceptores representa uma alternativa atraente e neste trabalho, discute-se o emprego desta estratégia na identificação de novos compostos-protótipos de fármacos antiinflamatórios, antitrombóticos e analgésicos, pertencentes à classe das $N$-acilarilidrazonas (NAH).

\section{A IDENTIFICAÇÃO DO ALVO-FARMACOLÓGICO}

O processo inflamatório crônico pode ser tratado por diferentes intervenções terapêuticas, visto sua complexidade e a diversidade de mediadores fisiológicos envolvidos ${ }^{10}$. A maneira mais clássica compreende o emprego de inibidores da prostaglandina-endoperóxido sintase (PGHS), ${ }^{11}$ enzima responsável pela transformação do ácido araquidônico (AA), liberado pela fosfolipase $\mathrm{A}_{2}\left(\mathrm{PLA}_{2}\right)$, em prostaglandinas (PG's) flogísticas, ${ }^{12,13}$ como os agentes antiinflamatórios não-esteróides (NSAI) clássicos ${ }^{14} \mathrm{e}$, recentemente, pelo uso de agentes NSAI seletivos para a isoforma-2, induzida ${ }^{15}$ da PGHS, representados pelo rofecoxib (1) ${ }^{16}$ e celecoxib (2), ${ }^{17}$ introduzidos em 1999, no Brasil, pela MSD e Pfizer/Searle, respectivamente.

Em função do seu mecanismo de ação, os agentes NSAI apresentam propriedades analgésica periférica e anti-agregante plaquetária. ${ }^{11}$
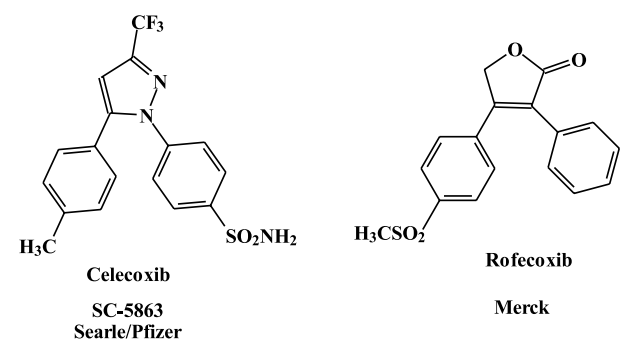

O envolvimento de outros mediadores como AMPc, cujo catabolismo é governado pelas fosfodiesterases (PDE's), ${ }^{18}$ a citocina pró-inflamatória fator de necrose tumoral- $\alpha$ (TNF- $\alpha),{ }^{19}$ interleucina1 e 10 (IL-1, IL-10) ${ }^{20}$ e a 5-lipoxigenase (5-LO), ${ }^{21}$ outra enzima oxidativa da cascata do ácido araquidônico, que compete com a PGHS para produzir os leucotrienos (LT's), representam alvos adequados para o tratamento de quadros inflamatórios. Os leucotrienos, por exemplo, apresentam propriedades quimiotáteis para neutrófilos e outras células sanguíneas com atividade proteolítica, participam da fisiopatologia da inflamação e representam alvos terapêuticos atraentes para o tratamento de doenças inflamatórias, ${ }^{22}$ incluindo asma e alergia (Figura 2).

A inibição da 5-LO como alvo terapêutico para o tratamento de quadros inflamatórios tem sido timidamente explorada, sendo o zileuton (3) ${ }^{23} \mathrm{o}$ único fármaco que manifesta seus efeitos terapêuticos, úteis para o tratamento da fase inflamatória da asma crônica, como inibidor de 5-LO.

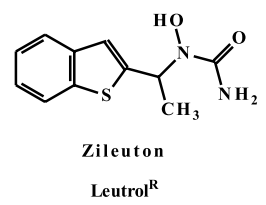

(3)

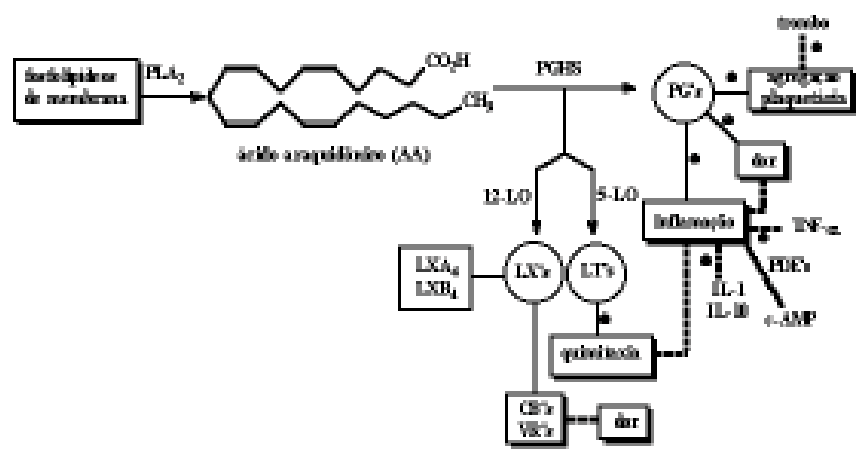

Figura 2. Alguns mediadores fisiológicos da inflamação, dor e formação de trombo.

Há algum tempo vimos estudando no Laboratório de Avaliação e Síntese de Substâncias Bioativas (LASSBio) da Faculdade de Farmácia da UFRJ o planejamento, a síntese e a determinação de propriedades farmacológicas de novos agentes NSAI, tanto análogos de agentes NSAI clássicos (4), (5) e (6), ${ }^{24,25}$ como, mais recentemente, inibidores seletivos de PGHS-2 (7) ${ }^{26}$. Em ambos os objetivos, temos utilizado o safrol (8), ${ }^{24,27}$ principal componente químico do óleo de sassafrás (Ocotea pretiosa), como matéria-prima, tendo logrado obter os compostos ativos ilustrados no Esquema $1 .^{24}$
(6)<smiles>C=C=CC(=O)C(=C(O)O)c1cc2c(cc1OC)OCO2</smiles>

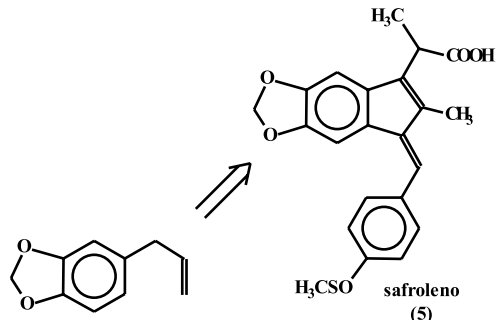

(5)

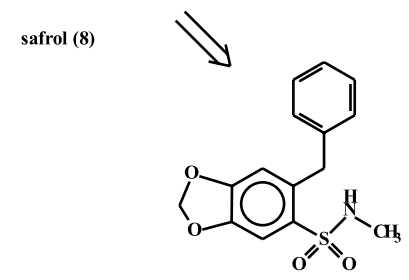

(7)

\section{Esquema 1}

No âmbito desta linha de pesquisas, visando à descoberta de novos candidatos a protótipos de agentes antiinflamatórios, analgésicos e anti-agregantes plaquetários, iniciamos, simultaneamente, a busca de novos inibidores de 5-LO, eleita desta feita como alvo-terapêutico, utilizando a hibridação molecular como estratégia de identificação de novos análogos ativos. ${ }^{22}$

\section{A HIBRIDAÇÃO MOLECULAR COMO ESTRATÉGIA PARA O PLANEJAMENTO DE NOVOS CANDIDATOS A AGENTES ANTIINFLAMATÓRIOS}

Relatos da literatura identificavam como inibidores de 5-LO os derivados BW-755c (9) ${ }^{28}$ e CBS-1108 (10). ${ }^{29}$ Análise cuidadosa da estrutura destas substâncias indicou um padrão de similaridade comum, representado pela função arilidrazona, que poderia estar associado à atividade descrita. De fato, no derivado 9 a função $N$ fenilidrazona (a) encontra-se internalizada no anel pirazolínico, en- 
quanto que no CBS-1108 (10) identifica-se sua presença numa subunidade espaçadora $N$-(2-tiofenila)-hidrazona (b). Com vistas a se investigar a contribuição deste padrão estrutural na atividade inibidora da 5-LO, planejou-se o híbrido (11), ${ }^{9}$ agregando as duas unidades (a), do BW-755c, agora contida no anel $N$-fenilpirazólico e (b) do CBS-1108 mantida como espaçadora entre o sistema pirazólico e substituintes arila, substituídos ou não, e heteroarila (Esquema 2). A natureza dos substituintes $\mathbf{W}$ ( inter-alia: $\mathbf{W}=\mathrm{H}, \mathrm{Me}, \mathrm{Cl}, \mathrm{Br}, \mathrm{OMe}$, $\mathrm{OH}, \mathrm{NO}_{2}, \mathrm{NH}_{2}, \mathrm{NMe}_{2}$ ) em orto-, meta- e para- do anel fenilíco (c) de 11 , foi eleita em função de suas propriedades eletrônicas e hidrofóbicas, de maneira a permitir que se avaliasse suas distintas contribuições para o perfil de atividade desejado.

Por conveniência sintética, nesta série inicial de compostos híbridos $(11),{ }^{30}$ foi incluído o substituinte nitro em C-4 do anel pirazólico, visto que a funcionalização em C-5, necessária à construção da unidade espaçadora desejada, depende, em condições de substituição nucleofílica aromática $\left(\mathrm{S}_{\mathrm{N}} \mathrm{Ar}\right)$, da ativação por grupos elétron-atratores ${ }^{31}$. Desta forma, o padrão molecular da série congênere inicial (11) foi desenhado. ${ }^{30}$

A síntese desta série (11) foi realizada empregando-se metodologia clássica, a partir do $N$-fenil-3-metil-5-hidroxi-pirazol (12), substância de fácil acesso sintético (Esquema 3). ${ }^{30}$

A condensação de fenilidrazina (13) com acetoacetato de etila conduziu ao derivado pirazólico funcionalizado $N$-fenil-3-metil-5hidroxipirazol (12) em $82 \%$ de rendimento. Esta substância, tratada com $\mathrm{POCl}_{3}$, forneceu o derivado clorado correspondente (14), que por nitração branda, empregando-se ácido nítrico em anidrido acético, originou, regiosseletivamente, o derivado nitrado 15. A substituição nucleofílica aromática do átomo de cloro em C-5 de 15 com hidrato de hidrazina, seguida de condensação catalisada por ácido da hidrazida intermediária (16) com diversos aldeídos aromáticos originou a série de derivados arilideno-1-fenil-3-metil-4-nitro-5pirazolilidrazinas $(11)^{32}$ (Esquema 3 ).

Os dezesseis novos compostos (11) foram obtidos em bons rendimentos globais e caracterizados espectroscopicamente. Para a etapa de avaliação farmacológica das propriedades antiedematogênicas desta série, necessitava-se definir a natureza da configuração da ligação dupla $\mathbf{N}=\mathbf{C}$ de 11. Embora derivados hidrazônicos sejam considerados substâncias de derivatização clássica de compostos carbonilados, quando estes são aldeídos (RCHO) ou cetonas, distintamente substituídas (RCOR'), podem-se obter dois diasterêoisomeros configuracionais, i.e. $Z$ e $E$ (Esquema 4). Desta forma, a primeira etapa da caracterização estrutural desta classe de compostos (11) compreendeu a determinação do grau de diastereosseletividade da etapa de condensação que conduz à formação da função hidrazona. ${ }^{30}$

A análise dos dados de ressonância magnética nuclear (RMN) de ${ }^{1} \mathrm{H} \mathrm{e}^{13} \mathrm{C}$ em DMSO-d $\mathrm{d}_{6}$ desta série (11) indicou a presença de um único isômero nesta classe de derivados hidrazônicos, que puderam ser caracterizados, pelo padrão de deslocamento químico do hidrogênio iminíco -C=NH- $(\delta 8,2-8,8)^{33}$ e do hidrogênio amídico -NH$(\delta 10,8-11,5)$ como sendo o diasterêoisomero $Z$. Outrossim, os dados de $\mathrm{RMN}$ de ${ }^{1} \mathrm{H}$ indicaram a ausência da forma tautomérica diazo (Esquema 4), confirmada pelos dados do espectro de infravermelho (IV)

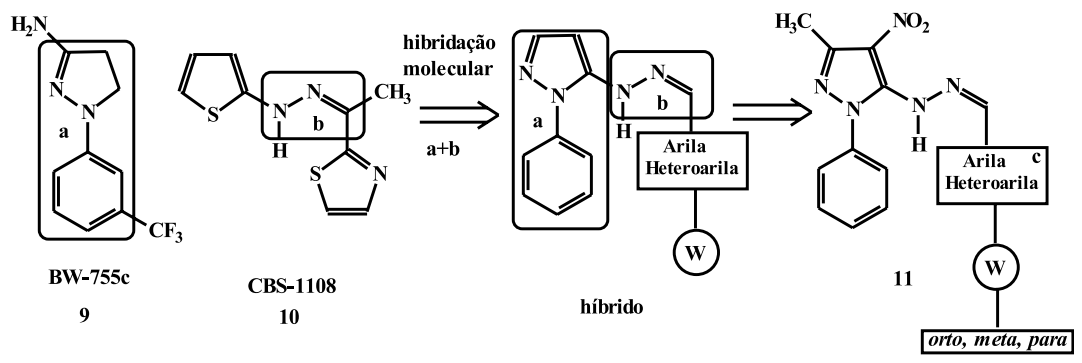

Esquema 2
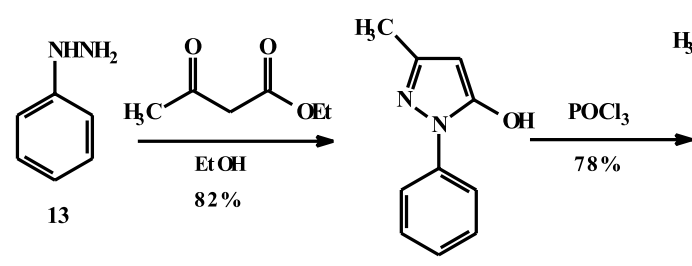

12

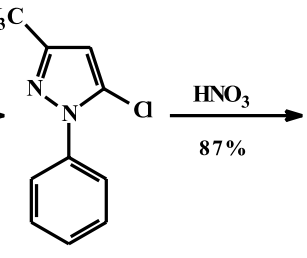

14

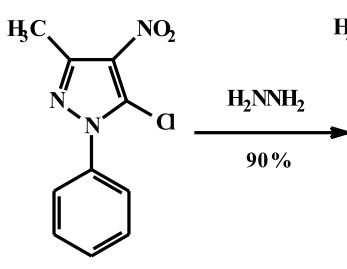

15<smiles>Cc1nn(-c2ccccc2)c(N)c1[N+](=O)[O-]</smiles>

16
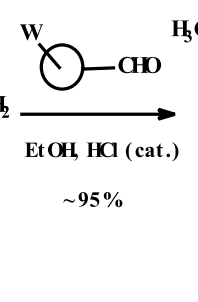

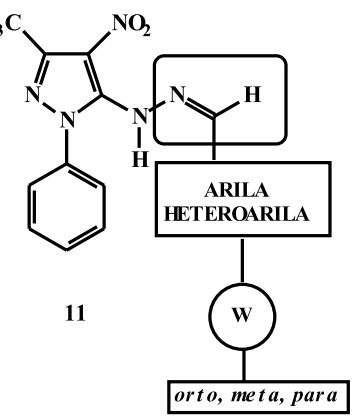




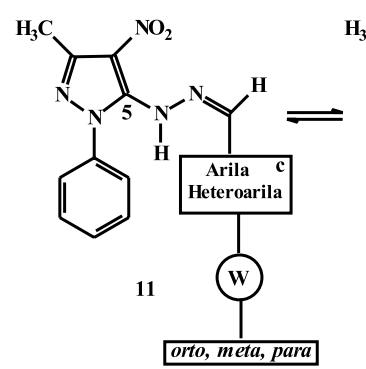

isômero-Z

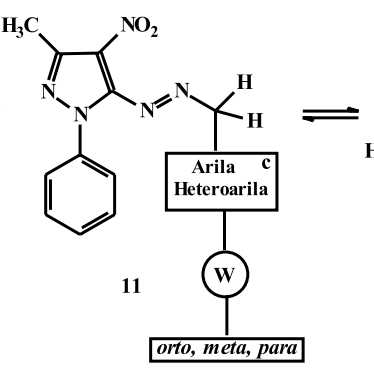

tautômero diazo

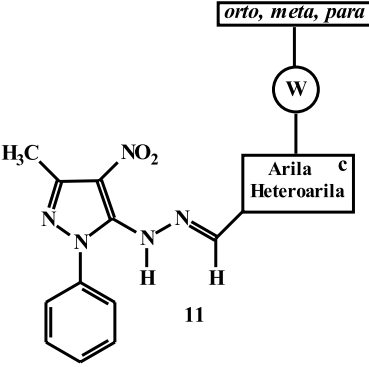

isômero- $E$

Esquema 4
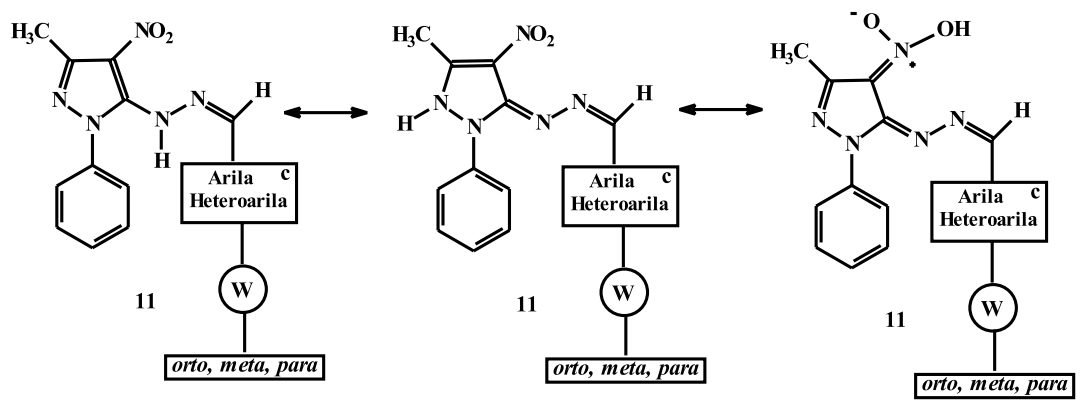

Esquema 5

desta série de compostos. No espectro de $\mathrm{RMN}{ }^{13} \mathrm{C}$ os sinais típicos do sistema pirazólico eliminaram a possibilidade de tautômeros envolvendo os átomos de nitrogênios aromáticos (Esquema 5).

Uma vez estruturalmente caracterizados e com o grau de pureza verificado, os novos compostos da série 11 foram avaliados farmacologicamente empregando-se o modelo do edema da pata de rato induzido por carragenina ${ }^{34}$ e o teste de inibição das contorções abdominais em camundongos induzidas por uma solução a $0,6 \%$ de ácido acético ${ }^{35}$ e apresentaram modesto efeito antiedematogênico ${ }^{32}$, ${ }^{36}$, destacando-se no bioensaio de contorções o derivado paradimetilaminofenila (11b) substituído na subunidade imínica. Dentre os derivados ativos, em ambos os ensaios, não se identificou atividade significativa em nenhum composto orto- ou meta- mono-substituído na sub-unidade fenílica (c), privilegiando a substituição em para- nas séries subseqüentes. Nesta série de derivados hidrazônicos (11), observou-se que o derivado possuindo a sub-unidade 2-furila (LASSBio-2, 11c) ${ }^{37,38}$ na função imínica, apresentou importante atividade anti-agregante plaquetária, em modelo induzido pelo ácido araquidônico em plasma de coelhos rico em plaquetas, inibindo a agregação plaquetária em $98 \%$ na concentração de $100 \mu \mathrm{M}$.

O mecanismo de ação antitrombótica do composto LASSBio-2 envolve, provavelmente, o $\mathrm{Ca}^{2+}$ plaquetário, conforme evidenciado para o isóstero pirídinico simplificado (17), capaz de inibir a agregação plaquetária, no mesmo modelo, em $80 \%$ na concentração de $80 \mu \mathrm{M}^{39}$, possivelmente devido à presença de sítio de coordenação do tipo $\mathbf{N}^{1}-\mathbf{O}^{4}$, contando com a participação do anel 2-furila de 17 (Esquema 6). Evidências experimentais em suporte a esta hipótese foram obtidas, quando o análogo vinílogo (LASSBio-3, 11d) foi bioensaiado, não apresentando atividade anti-agregante plaquetária significativa.

Por outro lado, a caracterização da relação entre a atividade antiagregante plaquetária destes derivados $\mathrm{HZ} \mathrm{(11)} \mathrm{com} \mathrm{o} \mathrm{Ca}^{+2}$ foi motivo de encorajamento, visto que foi demonstrado que a 5-LO é uma<smiles>Cc1nn(-c2ccccc2)c(N/N=C/c2ccc([Al])cc2)c1[N+](=O)[O-]</smiles><smiles>Cc1nn(-c2ccccc2)c(N/C=N/c2ccco2)c1[N+](=O)[O-]</smiles>

11c LASSBio-2<smiles>Cc1nn(-c2ccccc2)c(N/N=C/C2CC3CCC2CC3)c1[N+](=O)[O-]</smiles>

11d LASSBio-3<smiles>C(=N/Nc1ccccn1)\c1ccco1</smiles>

17 LASSBio-316

enzima dependente de $\mathrm{Ca}^{+2}$ citossólico ${ }^{40,41} \mathrm{e}$ do fator transmembrânico de ativação (FLAP).

Cabe destacar que o derivado (17, LASSBio-316) apresentou $\mathrm{IC}_{50} 0,35 \mu \mathrm{M}$ no ensaio da inibição da agregação plaquetária induzida por ácido araquidônico em plasma de coelho rico em plaquetas ${ }^{38}$, com 


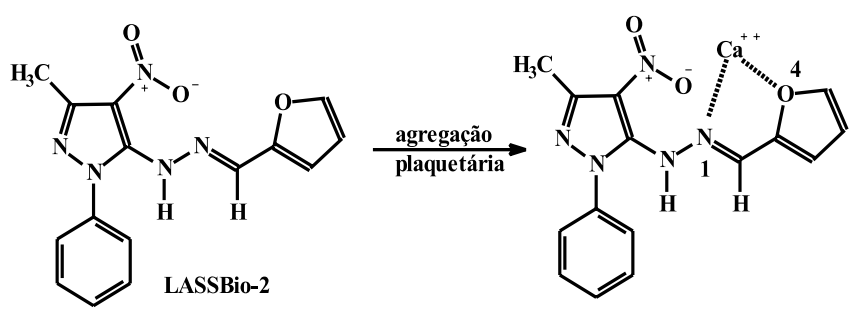

Esquema 6

potência comparável àquela do ozagrel (18), fármaco antitrombótico, recentemente lançado. ${ }^{42}$

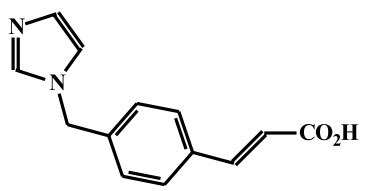

18

Estes resultados promissores nos levaram, numa etapa seguinte, a investigar a contribuição farmacofórica da função hidrazona, espaçadora, de 11. Para tanto, análogos em que a sub-unidade estrutural b (Esquema 7) foi simplificada para arilamina (19) foram sintetizados e bioensaiados. A contribuição farmacofórica da sub-unidade espaçadora arilidrazona presente nos derivados da série 11 foi constatada pela reduzida atividade observada nos derivados 5arilamínicos 19.43

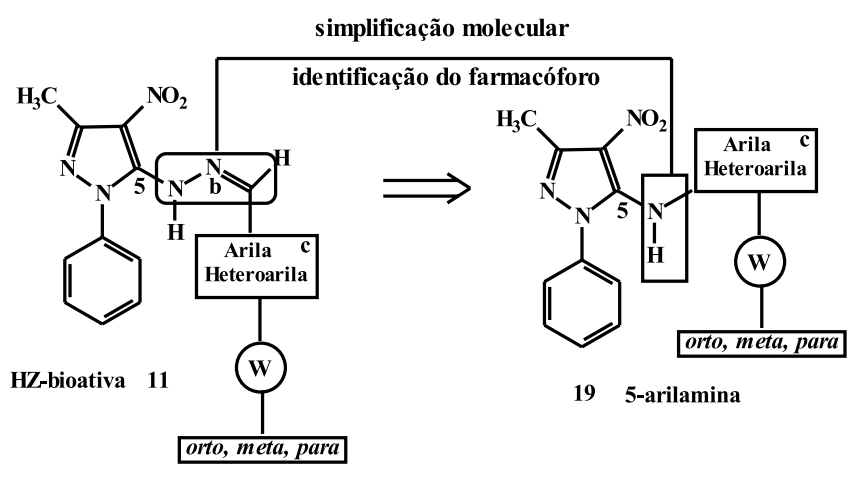

Esquema 7

Outrossim, comparando-se as estruturas dos compostos 5hidrazônicos (11) e 5-amínicos correspondentes (19), pode-se observar que, em ambas as séries, existe a possibilidade de uma ligação-H intramolecular entre os substituintes em C-4 (aceptor) e C-5 (doador), que poderia estar relacionada às propriedades farmacológicas identificadas. Estudos teóricos por modelagem molecular confirmaram esta possibilidade, indicando que o grupo N-H em C-5 e a função 4-nitro do núcleo pirazólico têm distância média de, aproximadamente, $2 \AA$, favorecendo a formação de ligações- $\mathrm{H}^{44}$ capazes de introduzir um certo grau de rigidez conformacional e influenciar as atividades analgésica e antiedematogênica observadas (Figura 3). Desta forma, uma série de compostos 5-tioarila-pirazólicos $(20)^{45}$ foi sintetizada e os resultados da avaliação farmacológica, empregando-se os mesmos protocolos farmacológicos, indicaram para o derivado para-bromofenila (20a) uma atividade analgésica da ordem de $58 \%$ (100 mmol $/ \mathrm{kg}$ ) na inibição das contorções induzidas em camundongos. Tais resultados descartaram a dependência de conformações envolvendo ligações-H intramoleculares dos orto- substituintes em C-4/C-5 do anel pirazólico nesta atividade, permitindo que futuras modificações estruturais pudessem ser realizadas ao nível destes substituintes do anel acil-heterocíclico.

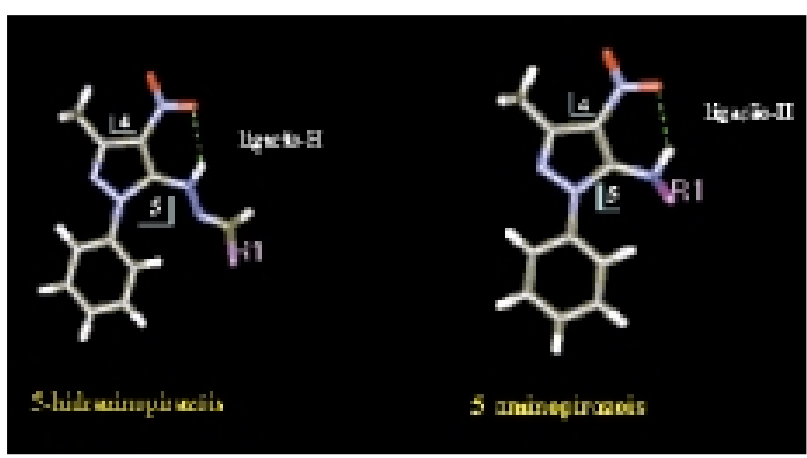

Figura 3. Ligação-H intramolecular nos derivados hidrazônicos (HZ) (11) e 5-arilamina (19).

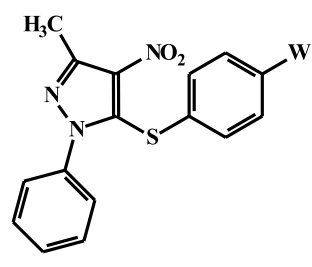

20a $\mathbf{W}=\mathbf{B r}$

Os resultados disponíveis sobre o perfil farmacológico desta primeira série de derivados hidrazônicos (11) indicaram que o padrão da unidade imínica (c, Esquema 2) contribuía para o perfil de atividade apresentado. Outrossim, se para a analgesia o anel fenílico devia ser mono-substituído na posição para, sendo o mais ativo aquele com substituinte para-dimetilaminofenila, para a agregação plaquetária o anel furânico se mostrou farmacoforicamente relevante, desde que conjugado com a ligação dupla $\mathbf{N}=\mathbf{C}$. Visando verificar-se a atividade antiinflamatória desejada, especialmente os eventuais efeitos sobre a bioformação de leucotrienos, por inibição da 5LO, os derivados desta série (11) com o anel fenílico da subunidade c (Esquema 2) dissubstituído por grupos oxigenados (e.g. 11e) $)^{46}$, foram bioensaiados. Considerando que este padrão de substituição permite que os compostos apresentem propriedades redox particulares, empregou-se o modelo de pleurisia induzida por carragenina em ratos, determinando-se a taxa de inibição da migração de leucócitos e do volume de exsudato pleural. O composto LASSBio-132 (11e) mostrou-se capaz de inibir ambas as respostas em 96,6 e 93,4\%, respectivamente, em doses de $40 \mu \mathrm{mol} / \mathrm{kg}$. ${ }^{46}$

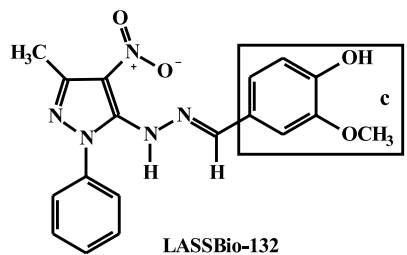

ASSBio-132
LASSBio-128<smiles>COc1ccc(/C=N/Nc2c([N+](=O)[O-])c(C)nn2-c2ccccc2)cc1O</smiles><smiles>COc1ccc(/C=N/Nc2c([N+](=O)[O-])c(C)nn2-c2ccccc2)cc1OC</smiles>

LASSBio-120 
Cabe ressaltar que o regioisômero de 11e, i.e. LASSBio-128 (11f), assim como o derivado metoxilado correspondente (LASSBio-120, $11 \mathrm{~g}$ ) não apresentaram o mesmo padrão de atividade, o que sugere que os efeitos farmacológicos observados nestes ensaios, sejam reflexo das propriedades redox da unidade aza-estirênica contida na cadeia hidrazônica, dependendo, por sua vez, do padrão de regio-oxigenação do anel fenílico terminal.

Finalmente, vale registrar, ainda, que derivados nos quais a subunidade (c, Esquema 2) era saturada ${ }^{30}$ não apresentaram atividade significativa em nenhum dos bioensaios realizados, indicando que nesta série de derivados hidrazônicos (11), as atividades estudadas dependem da presença da sub-unidade aromática ou heteroaromática (c, Esquema 2) na função hidrazônica.

Os resultados encorajadores obtidos com estas séries de derivados hidrazônicos permitiram a identificação de propriedades analgésicas, antiinflamatórias e anti-agregante plaquetária, relacionadas com a presença da subunidade espaçadora hidrazona e dependente da natureza e do padrão de substituição do grupo terminal aromático, justificando a continuação destes estudos, visando a otimização das propriedades farmacológicas identificadas.

\section{O Biososterismo como Estratégia de Otimização do Composto- Protótipo: $O$ Desenho Estrutural das $N$-acilarilidrazonas (NAH) Antiinflamatórias, Analgésicas e Antitrombóticas}

Tendo logrado sucesso na identificação da nova série (11) de análogos ativos hidrazônicos pelo emprego da hibridação molecular, a próxima etapa do estudo visou à sua otimização (Figura 1). Tomandose em conta que a presença da sub-unidade nitroazol nesta classe de derivados hidrazônicos (11) pudesse representar atributo de toxicidade, ${ }^{8}$ conforme relatado para fármacos com este padrão molecular, particularmente derivados $O$-, $N$-heterociclícos nitrados, com atividade antiparasitária e antifúngica (e.g. metronidazol e tinidazol, 21, 22), ${ }^{47}$ esta classe de derivados hidrazônicos ativos (11) foi estruturalmente modificada por simplificação molecular. Buscou-se eliminar a presença do grupamento nitro em C-4, potencialmente toxicofórico, preservando-se e otimizando-se a atividade farmacológica identificada.<smiles>Cc1cnc([N+](=O)[O-])n1CCO</smiles>

21<smiles>CCS(=O)(=O)CCn1c([N+](=O)[O-])cnc1C</smiles>

22
Admitindo que o grupamento nitro possa ser visualizado como isóstero do grupamento carboxilato (Esquema 8), ${ }^{6,48}$ identificou-se a possibilidade de se introduzir em C-4 do núcleo pirazólico uma função carbonila $(\mathbf{C}=\mathbf{O})$, mimetizando a insaturação $(\mathbf{N}=\mathbf{O})$ presente no grupamento nitro dos análogos-ativos identificados, diretamente ligada àquela farmacoforicamente relevante, i.e. arilidrazona. Este planejamento estrutural ilustrado no Esquema 9 originou a série de $\mathrm{N}$ acilidrazonas (NAH) pirazólicas (23), primeira série desta classe obtida no laboratório. ${ }^{30}$
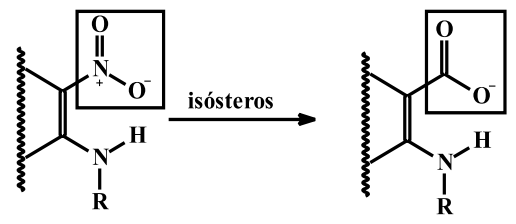

Esquema 8

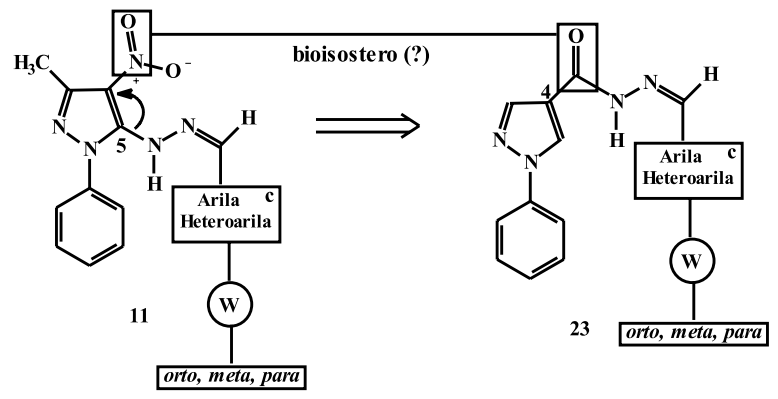

Esquema 9

A síntese desta primeira série de derivados NAH (23) iniciou-se pela construção do anel pirazólico, realizada a partir da mesma fenilidrazina (13), empregada para a síntese de 11, tratando-a desta feita com 1,1,3,3-tetrametoxipropano (Esquema 10), o que levou à obtenção do $N$-fenilpirazol (24). Regiofuncionalização da posição C4 de 24, empregando-se as condições de Vilsmeier-Haack, originou o derivado $N$-fenil-4-formilpirazol (25), que, oxidado com o reagente de Jones, levou à obtenção do ácido carboxílico correspondente (26). A reação de esterificação de 26 com diazometano, originou o éster metílico correspondente (27), que, por hidrazinólise com hidrato de hidrazina, forneceu a hidrazida correspondente (28). Condensação deste intermediário-chave (28) com os aldeídos aromáticos desejados levou à série dos novos derivados NAH pirazólicos desejados (23). ${ }^{30}$
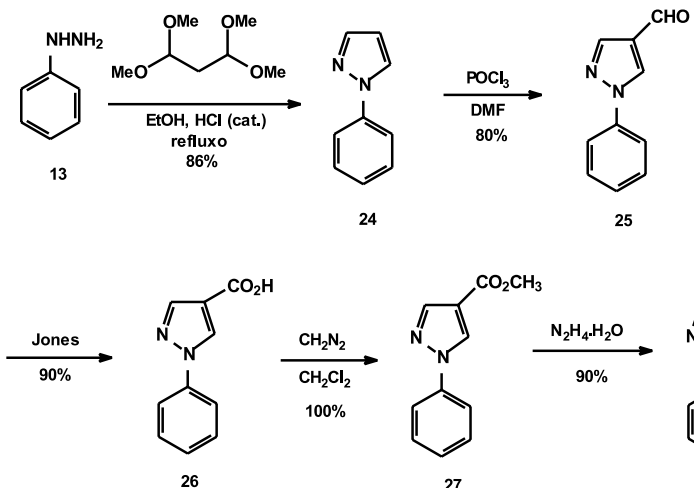

24

25
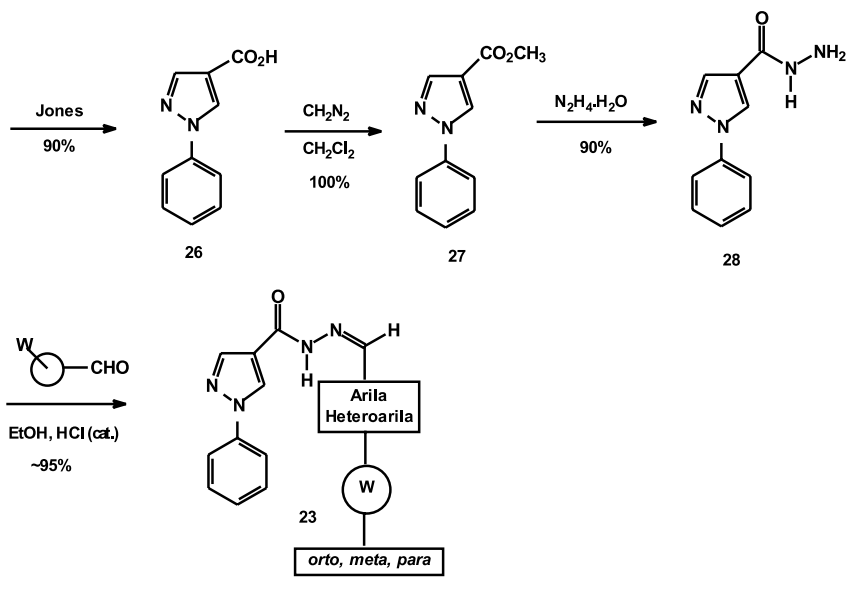

Esquema 10

Segundo o mesmo protocolo empregado com os derivados hidrazônicos iniciais (11), esta série de compostos NAH (23) foi espectroscopicamente estudada de maneira a se determinar a configuração da insaturação imínica.

A predominância do tautômero imínico e a configuração relativa da ligação dupla $\mathbf{N}=\mathbf{C}$ nesta série (23) foi determinada pela presença de forte absorção no espectro IV, a $3200 \mathrm{~cm}-1$ (N-H), associada aos sinais nos espectros de $\mathrm{RMN}{ }^{1} \mathrm{H}$ e ${ }^{13} \mathrm{C}$ em d 8,5-9,0 e 144,2-148,5, correspondendo ao $\mathbf{C}$-H imínico, o que excluiu a forma diazo-cetona 
e identificou a configuração da ligação dupla $\mathbf{N}=\mathbf{C}$ como $(E)$, para o isômero majoritário (Esquema 11). ${ }^{30}$

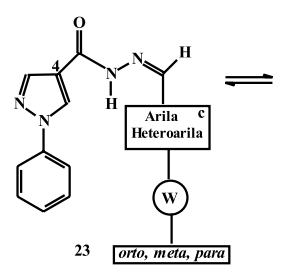

isômero- $Z$

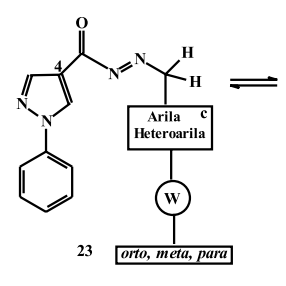

tautômero diazo-cetona

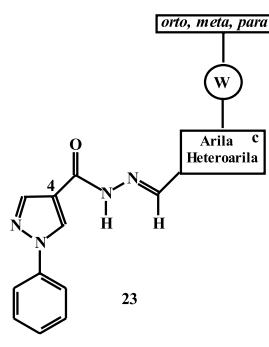

isômero- $E$
Esquema 11

Outra evidência substancial da predominância do isômero $(E)$ nesta série (23) foi obtida pelo emprego da cromatografia de alta resolução em fase gasosa, durante investigação sobre a cinética de formação dos diastereoisômeros $(E) /(Z)^{49}$. Foi possível evidenciar que o diasterêoisomero que apresentava o sinal atribuído ao hidrogênio imínico em $c a$. $\delta 8,5-9,0$ no espectro de $\mathrm{RMN}{ }^{1} \mathrm{H}$, em $\mathrm{CDCl}_{3}$, era aquele que apresentava um pico $\mathrm{m} / \mathrm{z}$ 187, com abundância relativa de $41 \%$ na espectrometria de massas. Este processo de fragmentação, típico para rearranjo de McLafferty ${ }^{50}$ envolvendo o átomo de oxigênio carbonílico e o hidrogênio- $\gamma$, exige a geometria adequada, correspondendo àquela do diastereoisômero- $E$ (Esquema 12).<smiles>Cc1nc2ccccn2c1C(=O)N/N=C/c1ccc(Br)cc1</smiles>

39a

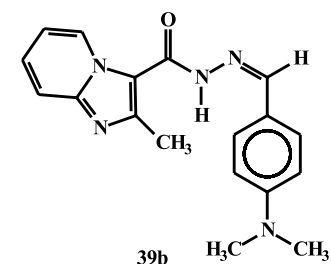

$39 \mathrm{~b}$
Esquema 12

Finalmente, estudos de modelagem molecular, por métodos semiempíricos AM1, reiteraram a predominância da configuração $(E)$ da ligação dupla $\mathbf{N}=\mathbf{C}^{51}$.

Cabe destacar que a possibilidade de tautomeria nesta série (23) conduziria à formação de espécies reativas, tóxicas, representadas por diazo-cetonas (Esquema 11). Estas atuam como aceptores de Michael, reagindo com nucleófilos biológicos (e.g. bases purinícas $)^{8}$ e formando adutos irreversíveis de elevado potencial toxicofórico. Caso estes ocorressem invalidariam a estratégia de modificação molecular eleita para reduzir o potencial tóxico da função nitroazol.

Os mesmos critérios empregados na escolha dos substituintes $\mathbf{W}$ do anel fenílico da unidade iminíca na série hidrazônica anterior (11) foram adotados nesta série (23), elegendo-se o aldeído aromático a ser condensado com a hidrazida, em função das características eletrônicas e hidrofóbicas de seus substituintes. Ademais, priorizou-se a obtenção de derivados mono-para-substituídos na unidade fenílica da imina, exceto pela presença do substituinte 3,5-di-tert-butil-4-hidroxibenzeno, eleito por suas propriedades redox particulares, ${ }^{52}$ identificadas como relevantes para a atividade antiedematogênica medida na pleurisia induzida por carragenina, conforme observado para 11e. ${ }^{46}$<smiles>Cc1nn(-c2ccccc2)c(N/N=C\c2cc([14CH3])c(O)c(CC(C)(C)C)c2)c1[N+](=O)[O-]</smiles>

Uma vez caracterizada estruturalmente, esta série de compostos (23) foi bioensaiada, utilizando-se os mesmos protocolos farmacológicos usados com os derivados hidrazônicos anteriores (11).

Os ensaios farmacológicos efetuados com esta série (23) permitiram identificar dois novos protótipos, destacando-se a atividade antiagregante plaquetária de LASSBio-35 (23a), que apresenta, novamente, no grupo imínico terminal o anel 2-furila. ${ }^{53,54}$ Por outro lado, a variação da natureza deste substituinte para para-dimetilaminofenila (LASSBio-30, 23b) permitiu identificar-se um atraente perfil analgésico, tendo este derivado NAH se mostrado 5,2 vezes mais potente que a dipirona, analgésico clássico usado como padrão no ensaio de contorções abdominais induzidas pela acetilcolina (ACh) em camundongos ${ }^{55}$.

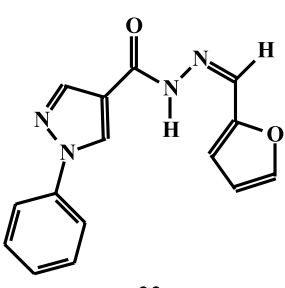

23 a<smiles>CN(C)c1ccc(/C=N\N([Tl])C(=O)c2cnn(-c3ccccc3)c2)cc1</smiles>

$23 \mathbf{b}$
Os resultados farmacológicos obtidos validaram esta nova série de derivados NAH (23), que manifestaram importantes propriedades analgésica e anti-agregante plaquetária, suplantando a série hidrazônica original (11), sem apresentar perfil de toxicidade potencial, devido à ausência do grupamento nitro presente na primeira. Ademais, estes resultados indicaram que a estratégia de modificação molecular adotada, visando à otimização da série hidrazônica inicial, mostrou-se adequada.

A determinação do caráter lipofílico desta série de derivados NAH (23) foi investigada ${ }^{56}$ pelos três principais métodos de determinação deste parâmetro, quais sejam, shake-flask, cromatografia em camada delgada por fase reversa e cromatografia líquida de alta eficiência (CLAE). Foi possível, ainda, determinar-se a constante fragmental para a função hidrazona, uma lacuna que até então comprometia estudos de QSAR em derivados com este grupamento funcional. ${ }^{57}$

Da mesma maneira que realizado com a série hidrazônica original (11), a evidência da natureza farmacofórica da função NAH foi obtida quando os derivados amídicos correspondentes (29), obtidos pela supressão da insaturação imínica (a, Esquema 13), mostraramse inativos nos mesmos bioensaios e nas mesmas concentrações.
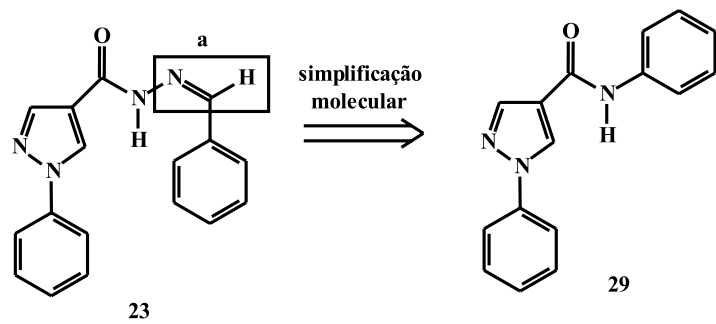

Esquema 13

\section{SÉRIE ISÓSTERA 3-FENIL-1,2,4-OXADIAZOL (30)}

Tendo identificado, pela estratégia de hibridação molecular, uma nova classe de compostos protótipos com propriedades antiinflamatória, analgésica e anti-agregante plaquetária (23), nos quais a função NAH se apresentava como importante farmacóforo, decidiu-se investigar, em seguida, a variação da unidade $N$ fenilpirazólica (a, Esquema 14), empregando-se para tal o bioisosterismo clássico de anéis ${ }^{6}$ na definição dos novos padrões 
estruturais. Inicialmente, decidiu-se manter a mesma característica hidrofóbica da sub-unidade aromática (a, Esquema 14) da série protótipo (23), i.e. $6 \pi+6 \pi$ elétrons. Por outro lado, a variação da subunidade aromática (b, Esquema 14) também se fundamentou em trocas isostéricas. ${ }^{58}$

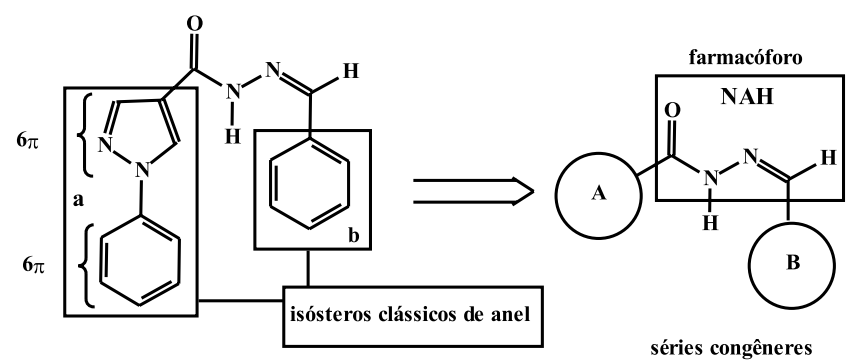

23

\section{Esquema 14}

Esta estratégia definiu a nova série 3-fenil-1,2,4-oxadiazol (30), em que o anel 1,2,4-oxadiazólico é isóstero clássico do núcleo pirazólico (Esquema 15). ${ }^{58,59}$ A localização do substituinte fenílico em C-3 no anel tri-heterocíclico de 30 assegurava maior similaridade estrutural com a série protótipo 23 , ambas com átomo de nitrogênio N-2 na mesma localização (Esquema 15).

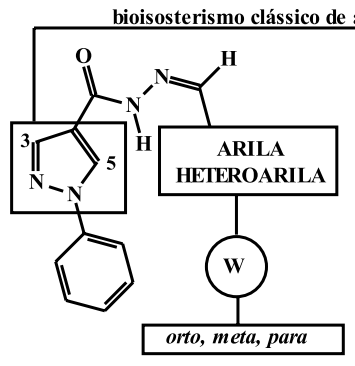

23

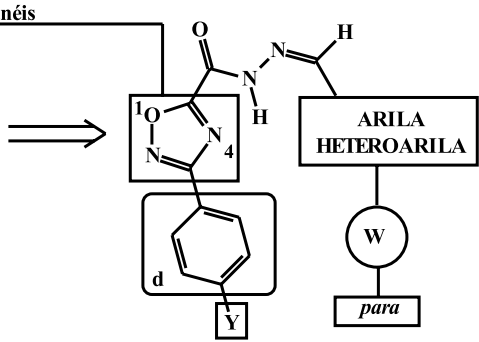

30

\section{Esquema 15}

Esta nova série de derivados NAH (30) tem, ainda, como característica estrutural relevante, a natureza distinta dos pseudo-ortosubstituintes do sistema fenil-heterociclo, agora com dois heteroátomos distintos nas posições O-1 e N-4. Na série $N$ fenilpirazólica 23 os orto-substituintes da cadeia farmacofórica, em C-3 e C-5, átomos de hidrogênio, eram idênticos (Esquema 15). Esta particularidade estrutural introduzia para a cadeia NAH de 30 a possibilidade de diferentes conformações, dignas de serem investigadas no estudo da relação estrutura-atividade pretendido, a saber, $S$-cis ou $S$-trans, quando se elege o $N$-heteroátomo adjacente como integrante do "dieno" (Figura 4). A simples inspeção de modelos moleculares 3D dos possíveis confôrmeros de um mesmo diastereoisômero (e.g. $Z$ ) indicava que no confôrmero (Z)-S-trans, distintamente do (Z)- $S$ cis, havia distância favorável à formação de uma ligação-H intramolecular entre o átomo de hidrogênio do grupamento -NH e o átomo N-4 do anel heterocíclico, o que permitia antecipar uma diferença de energia razoável entre os dois confôrmeros de um mesmo diastereoisômero. ${ }^{59}$ Estas distintas características estruturais resultavam numa diferença da geometria molecular, eventualmente suficiente para influenciar a resposta biológica.

A síntese desta nova série de derivados NAH foi realizada (Esquema 16$)^{59}$ priorizando-se a obtenção de derivados para-substituídos (W) no anel terminal da função imínica (Esquema 15). Outros-

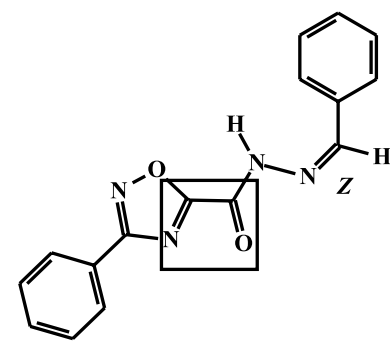

conformêro $S$-cis

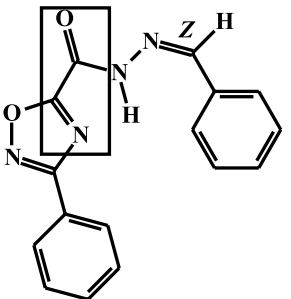

conformêro $S$-trans

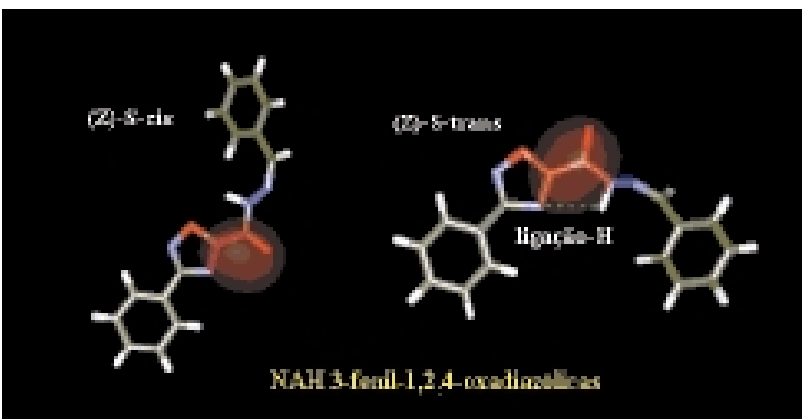

Figura 4. Confôrmeros possíveis da série NAH 3-fenil-1,2,4-oxadiazol (30).

sim, esta nova classe de derivados NAH (30) facultava a introdução de uma nova variável estrutural, em relação à série pirazólica original (23), digna de ser investigada quanto aos eventuais efeitos sobre seu perfil biológico, visto que poderíamos, variando a benzonitrila (31) de partida, obter derivados substituídos (30, $\mathbf{Y}=\mathrm{H}, \mathrm{Me}, \mathrm{OMe}$ e $\left.\mathrm{NO}_{2}\right)$ no anel fenílico (d, Esquema 15) do sistema heterocíclico. ${ }^{59}$

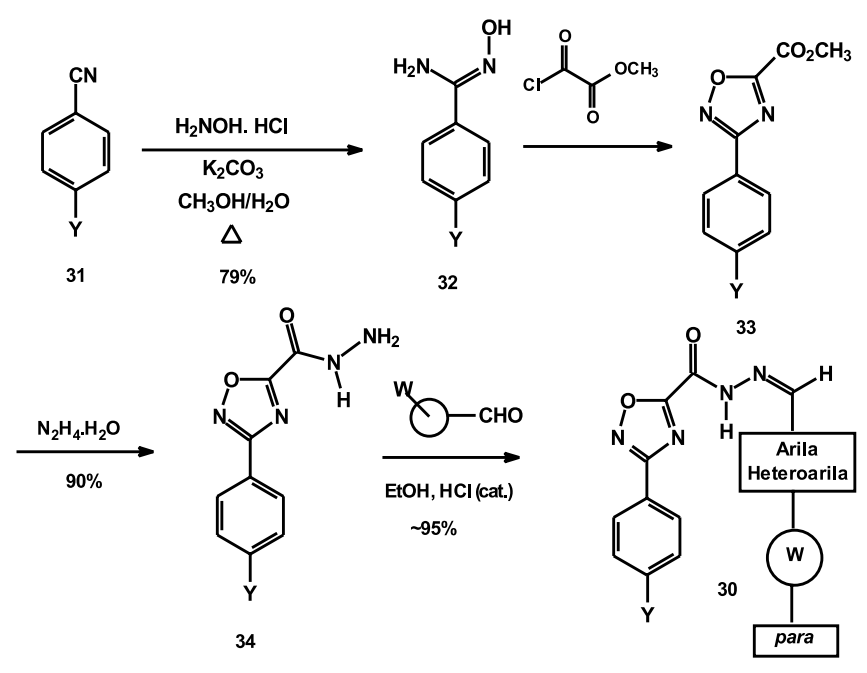

Esquema 16

O tratamento da benzonitrila $\left(31, \mathbf{Y}=\mathrm{H}, \mathrm{Me}, \mathrm{OMe}, \mathrm{NO}_{2}\right)$, devidamente funcionalizada, com o cloridrato de hidroxilamina e carbonato de sódio, na presença de metanol aquoso, produziu a benzamidoxima correspondente (32). A reação das benzamidoximas (32) com cloreto de metiloxalila originou os ésteres metílicos (33), que, após tratamento com hidrato de hidrazina, produziram as hidrazidas (34). Estas, por condensação catalisada por ácido com os aldeídos adequados, produziram a nova série heterocíclica de derivados NAH (30). ${ }^{59}$ 
A análise dos dados espectroscópicos desta série (30), a exemplo das anteriores, evidenciou que a configuração da ligação imínica era $Z$ $\mathrm{e}$, novamente, a forma tautomérica eno-hidrazona predominava conforme indicou a presença do sinal a $\delta 12,5-13,0$, trocável com $\mathrm{D}_{2} \mathrm{O}(-$ NH-) no espectro de RMN ${ }^{1} \mathrm{H}$. Curiosamente, para o derivado $30 \mathrm{em}$ que $\mathbf{Y}=\mathrm{OMe}$ ou Me e Ar-W = Ph, observamos a formação de mistura diastereoisomérica com predominância do isômero- $E$. Vale destacar que esta série de derivados (30) apresentou polimorfismo, pois a relação diastereoisomérica mostrou-se dependente do método de cristalização empregado. ${ }^{59}$ Ademais, o espectro de RMN ${ }^{1} \mathrm{H}$ da mistura diastereoisomérica, em DMSO- $\mathrm{d}_{6}$, mostrava-se simplificado quando a solução era estocada, indicando a possibilidade de isomerização da ligação dupla, tempo dependente. ${ }^{59}$

Os resultados da avaliação farmacológica desta nova série de derivados NAH (30), nos bioensaios de contorções abdominais induzidas por ácido acético, indicaram que os derivados LASSBio176 (30a) e LASSBio-171 (30b), apresentaram superior atividade analgésica, da ordem de 52,3\% e 50\%, respectivamente, na concentração de $100 \mathrm{mmol} / \mathrm{kg}$, quando comparados aos demais membros da série estudada, indicando que o substituinte do anel fenílico da unidade oxadiazólica não alterou o perfil de atividade analgésica observada, potencializando-o quando o substituinte (30) $\mathbf{Y}=\mathrm{OMe}$ e $\mathbf{W}=\mathrm{NMe}_{2}{ }^{58}$. Contudo, o grupamento para-dimetilaminofenila da unidade imínica (30c) mostrou-se, nesta série, menos relevante para a atividade analgésica do que o derivado LASSBio-30 (23b) da série pirazólica original, que inibiu em $63,9 \%$ as contorções induzidas em camundongos na concentração de $100 \mathrm{mmol} / \mathrm{kg} .{ }^{58}$

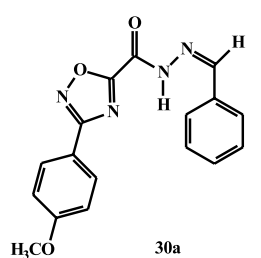

$30 \mathrm{a}$

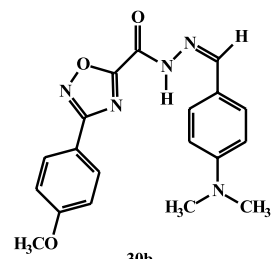

$30 \mathrm{~b}$

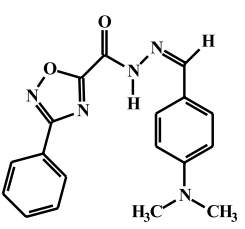

$30 \mathrm{c}$
Estudos teóricos por modelagem molecular nesta série $30^{59}$ confirmaram que a conformação preferencialmente adotada pela carbonila da função NAH é S-trans em relação ao sistema heterocíclico e que o diasterêoisomero $(Z)$ é o mais estável. Ademais, a conformação $S$-trans favorece sítio de coordenação possível $\mathbf{O}^{1}-\mathbf{O}^{4}$ ou $\mathbf{O}^{1}-\mathbf{N}^{4}$, além daqueles típicos da função $\mathrm{NAH}$.

Foram realizados estudos do padrão de fragmentação desta série $(30)^{60}$ na espectrometria de massas, indicando a presença de picos correspondentes à fragmentação via rearranjo de McLafferty, ${ }^{50}$ similares àqueles identificados para a série protótipo 23.

Os ensaios desta série na atividade anti-agregante plaquetária, realizados nos mesmos modelos farmacológicos das séries anteriores e com a mesma dose, não evidenciaram atividade significativa, sugerindo que a introdução do núcleo 1-fenil-1,2,4-oxadiazólico é deletéria para esta atividade.

\section{SÉRIE ISÓSTERA N-FENIL-1,2,3,-TRIAZÓLICA (35)}

Uma segunda série isostérica àquela pirazólica original (23) foi planejada, compreendendo os compostos triazólicos (35) (Esquema 17). ${ }^{61}$

O planejamento desta série triazólica (35) considerou a introdução de novo fator conformacional, distinto daqueles da série original $\mathrm{N}$ fenilpirazólica (23) e da série 3-fenil-1,2,4-oxadiazólica (30). Desta feita, o efeito pseudo-orto provocado em (30) pelos heteroátomos do anel heterocíclico do sistema oxadiazólico e ausente em (23), se biois os teris mo clássico de anéis

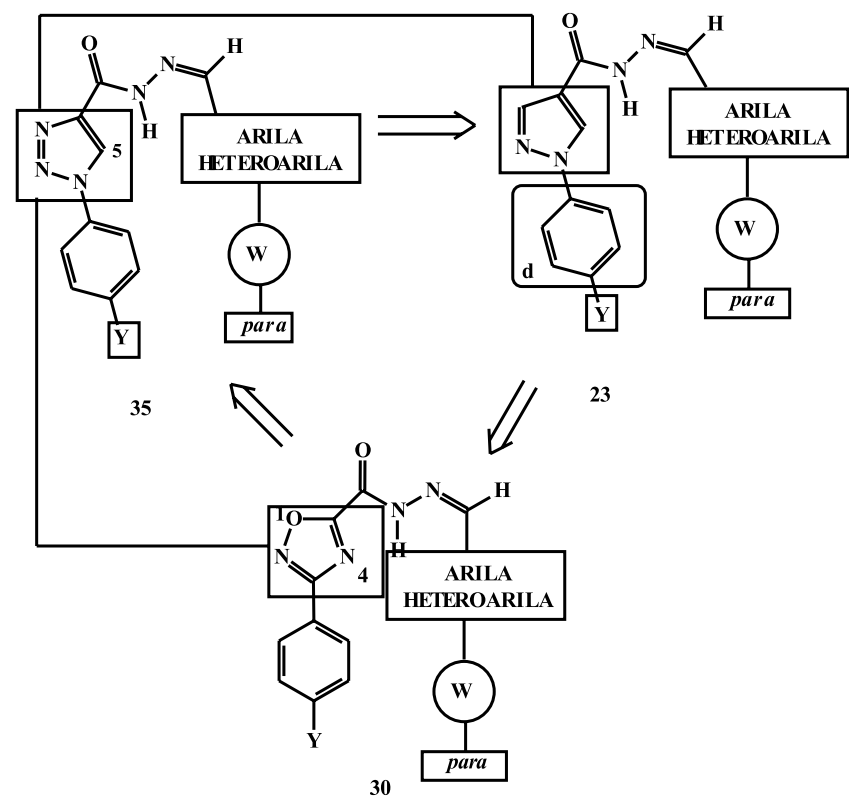

Esquema 17

verifica no sistema 1,2,3-triazólico (35) apenas com o par de elétrons não ligantes do átomo de N-3 do núcleo heterocíclico. Ademais, pode representar, ainda, um novo sítio de coordenação possível $\mathrm{N}^{1}-\mathrm{O}^{4}$.

A síntese da série de derivados NAH triazólicos $(35)^{61}$ foi realizada explorando metodologia sintética descrita por Lai e Anderson ${ }^{62}$, por meio do emprego de sucessivas interconversões de grupamentos funcionais, utilizando o aldeído (36) ${ }^{63}$ como produto de partida (Esquema 18).

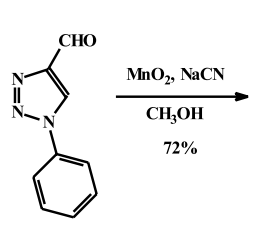

36
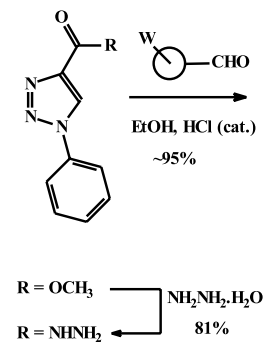

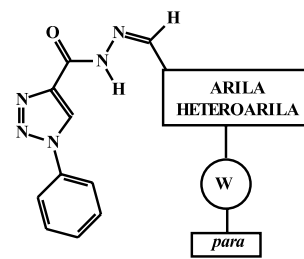

35
Esquema 18

Os resultados dos bioensaios obtidos com as três séries isostéricas (23), (30) e (35), indicaram, de forma geral, que a natureza do anel heterociclíco fenilado da função $N$-acilidrazona (A, Esquema 14) não alterava significativamente o perfil global de propriedades farmacológicas, distintamente do que parece sugerir a naturaza do substituinte do grupo imínico terminal (B, Esquema 14). ${ }^{64}$

\section{SÉRIE DE DERIVADOS NAH IMIDAZO[1,2-a]PIRIDINA (39)}

Visando modificar-se a natureza hidrofóbica da subunidade heteroaromática da função $N$-acilidrazona (A, Esquema 14), um sistema diaza-aromático com 10 elétrons- $\pi$ foi identificado por fusão do anel $N$-fenílico da série pirazólica original (Esquema 19), produzindo o sistema imidazo[1,2-a]piridina (39). ${ }^{65}$ 


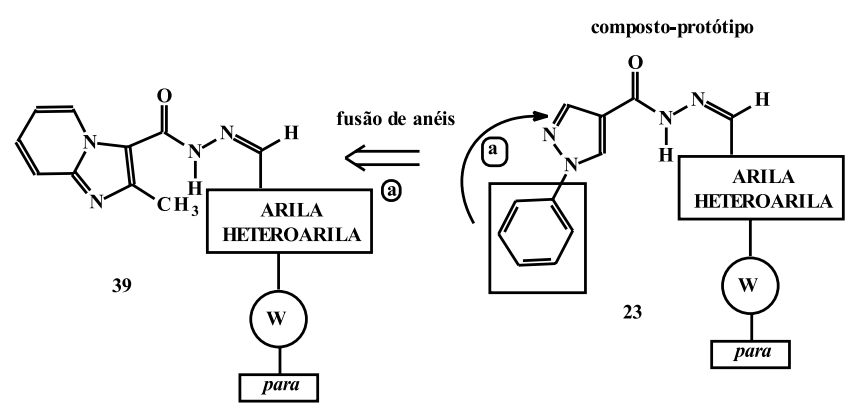

Esquema 19

O planejamento estrutural desta série de derivados NAH (39) considerou ainda a possibilidade da investigação do efeito orto do grupo metila do sistema heterocíclico no comportamento conformacional da cadeia farmacofórica e, por conseguinte, na atividade desta nova série de derivados NAH (39).

De fato, esta modificação estrutural permite uma liberação estérica do par de elétrons do átomo $\mathbf{N - 1}$, estericamente impedido nas três séries anteriores (23), (30) e (35), nas quais se verificou um ângulo de, aproximadamente, $170^{\circ}$ entre o substituinte fenila e o plano do anel heterocíclico. Cálculos de mecânica molecular demonstraram uma conformação preferida $S$-cis entre o grupo carbonila da função NAH e o grupamento orto-metila ${ }^{66}$.

A síntese dos derivados da série 39 está ilustrada no Esquema $20 . .^{65}$

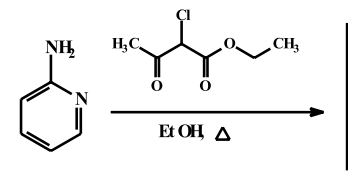

40

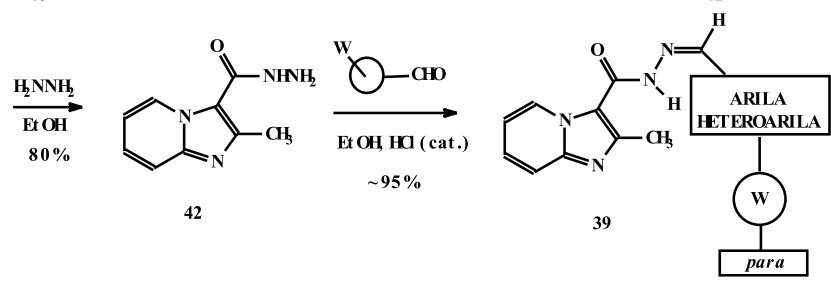

Esquema 20

A condensação quimiosseletiva da 2-aminopiridina (40) com 2cloro acetoacetato de etila originou, em bons rendimentos, o éster imidazo[1,2-a]piridínico (41), que, após tratamento com hidrato de hidrazina forneceu a hidrazida 42. Posterior condensação de 42 com os respectivos aldeídos aromáticos, catalisada por ácido, resultou nos novos derivados NAH desejados $39 .{ }^{65}$

Os resultados farmacológicos obtidos com esta série (39) permitiram evidenciar seu perfil analgésico, destacando-se o composto LASSBio-208 (39a), que possui o substituinte para-bromofenila no grupo imínico terminal, capaz de inibir em $45 \%(100 \mu \mathrm{mol} / \mathrm{kg})$ as contorções induzidas em camundongos. O derivado paradimetilaminofenila correspondente (39b) apresentou $38 \%$ de inibição das contorções abdominais neste bioensaio. ${ }^{65}$
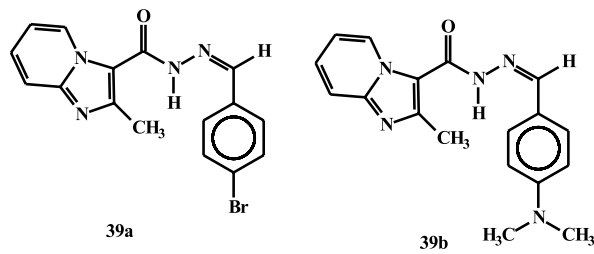

Com vistas a se investigar a contribuição da subunidade -NH-, sítio aceptor-H em interações com biorreceptores para esta atividade, promoveu-se sua $\mathrm{N}$-alquilação, obtendo-se, conforme ilustrado no Esquema 21, o derivado $N$-metilado (LASSBio-306, 43), que, quando avaliado farmacologicamente, se mostrou menos ativo que o LASSBio-208 (39a) ${ }^{65}$ Este resultado indicou que, ou a subunidade $\mathrm{NAH}$ interage por meio de ligações-H com o sítio receptor, sendo o cárater doador-H predominante ou, ao nível do receptor, este sítio de reconhecimento molecular é sensível a variações estéricas, sendo a atividade analgésica dependente da natureza não substituída do -NH- da função NAH.

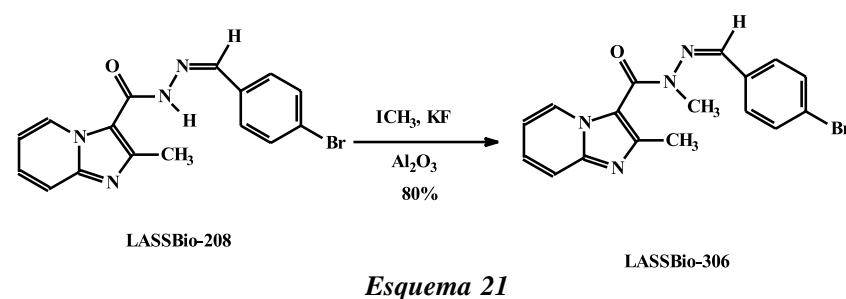

Por outro lado, a introdução de grupo metila na ligação imínica $\mathbf{N}=\mathbf{C}$ da função hidrazona, nesta série, exemplificada pelo composto LASSBio-247 (44), ${ }^{65}$ reduziu consideravelmente a atividade analgésica, sugerindo que o biorreceptor envolvido nesta resposta apresenta restrições estéricas ao reconhecimento nesta região de interação.<smiles>C/C(=N/NC(=O)c1c(C)nc2ccccn12)c1ccc(N(C)C)cc1</smiles>

\section{A IMPORTÂNCIA DO SUBSTITUINTE DA SUBUNIDADE ARIL-IMINA NO PERFIL DE ATIVIDADE DA SÉRIE DE DERIVADOS IMIDAZO[1,2-A]PIRIDÍNICOS (39)}

Reconhecendo-se que a função NAH tem uma relação azaviníloga com amidas (Esquema 22), presentes nos peptídeos como sítios de reconhecimento para hidrólise catalisadas por proteases ${ }^{67} \mathrm{e}$ que estas enzimas são alvos terapêuticos atraentes para a quimioterapia da inflamação, ${ }^{68}$ AIDS $^{69}$ (HIV-proteases) e doenças provocadas por protozoários, e.g. Plasmodium falciparum (falcipaína) e Trypanosoma cruzi (cruzipaína), ${ }^{70}$ causadores da malária e da doença de Chagas, respectivamente, decidimos, nesta série de derivados NAH 39, sintetizar derivados com substituintes orto- e ortopara-di-substituídos na subunidade arilimínica. Dessa forma, poderíamos investigar a contribuição do tipo "endereço" "71 desta subunidade estrutural nesta classe de derivados NAH, conforme sugeriam os resultados obtidos com as séries anteriores (23), (30) e (35) ao nível dos substituintes para-dimetilaminofenila e para-bromofenila, predominantemente analgésicos, e 2-furila, preponderantemente antiagregante plaquetário.

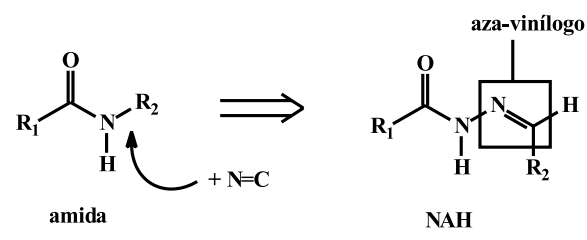

Esquema 22 
Considerando-se que as principais proteases de protozóarios são proteases cisteínicas (Cys-proteases), ${ }^{68,70}$ nas quais o nucleófilo é uma unidade cisteína, antecipou-se a possibilidade de que a insaturação imínica fosse reconhecida como "âncora" hidrofóbica pelo sítio ativo enzimático, oferecendo o centro eletrofílico da função NAH à enzima. Esta hipótese se fundamentava em resultados descritos por $\mathrm{Li}$ e colaboradores ${ }^{72}$ sobre a atividade inibitória de compostos estruturalmente relacionados (e.g. ZLI-48A, 45) em protease de protozoários.

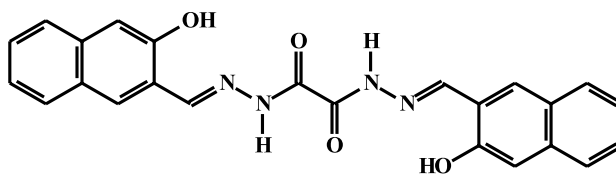

ZLI48A

Ensaios de inibição com os derivados orto-hidroxifenilados desta série 39 (e.g. LASSBio-334, 39c) sobre a cruzipaína (TCP, Cysprotease de $T$. cruzi) apresentaram-se qualitativamente positivos ${ }^{73}$.

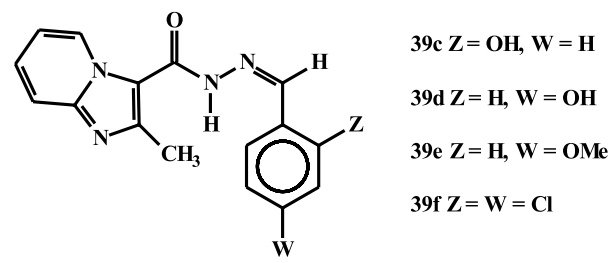

Curiosamente, derivados para-hidroxifenilados (39d), parametoxifenilados (39e) e orto-para-diclorofenilados (39f), entre outros, mostraram-se inativos nestes ensaios, indicando a participação da orto-hidroxila na atividade anti-protease ${ }^{73}$. A racionalização para o provável mecanismo molecular de ação dos derivados ortoarilidroxilados (39c) foi postulada como envolvendo uma espécie eletrofílica do tipo orto-quinonametídeo (46) (Esquema 23), originada, apenas, a partir do isômero $E$ de derivados NAH ortoarilidroxilados $(39 \mathrm{c})^{74}$. Ademais, determinou-se, teoricamente, que a forma orto-quinonametídeo (46) é energeticamente favorecida neste isômero e que seu centro eletrofílico principal, que origina o aduto mais estável com o tiolato ( $\mathbf{R S}^{-}$) como nucleófilo ${ }^{73,75}$, está situado no carbono eletrofílico da forma orto-quinonametídeo (46) e não na carbonila da função NAH, nem no sítio eletrofílico de espécie transiente do tipo diazocetona (47), reconhecidamente eletrofílica. Estes resultados referendaram o mecanismo molecular teoricamente proposto, ${ }^{75,76}$ no qual ocorre uma prototropia inicial, necessária à formação da espécie reativa orto-quinonametídeo, que, por sua vez, pode sofrer o ataque nucleofílico da Cys-25 do sítio catalítico da enzima, promovendo a formação de ligação covalente, estável no aduto. $^{75}$

Esta racionalização sugere para esta classe de inibidores, derivados hidrazônicos do salicilaldeído, inclusive do ZLI48A (45), uma inibição do tipo "suícida" 77 pela Cys-protease, operando de forma irreversível, aliás, como é desejável para agentes quimioterápicos. ${ }^{78}$

\section{MODIFICAÇÕES ADICIONAIS NA SUBUNIDADE ACIL- ARILA}

Visando ampliar a diversidade molecular nesta classe de derivados NAH bioativos, de maneira a que se obtivessem novos representantes variando-se o caráter eletrostático, a polarizabilidade, a superfície e hidrofobicidade da subunidade acil-aromática A (Esquema 14), capaz de ser reconhecida pelo sítio biorreceptor por interações $\pi$-staking, dependentes destas propriedades estruturais, decidimos investigar sistemas aromáticos nos quais se variassem os elétrons- $\pi$, conforme ilustrado na árvore isostérica do Esquema 24

Nesta ótica, o sistema pirazolo[3,4- $b]$ piridina $(48)^{79}$ originou-se do protótipo $N$-fenilpirazólico (23) por anelação (a, Esquema 24), respeitando-se a presença de um átomo de nitrogênio em C-5 do sistema pirazólico, a exemplo do que ocorria na série hidrazônica inicial (11). Adicionalmente, empregando-se o bioisosterismo clássico de anéis ${ }^{6}$ sobre esta série (b, Esquema 24), o sistema tieno[2,3$c$ ]pirazólico (49), também de 10 elétrons- $\pi$, desenhou-se como atraente objetivo. Por hibridação molecular (c, Esquema 24) dos núcleos pirazolo $[3,4-b]$ piridina $(48)^{79}$ e tieno[2,3-c]pirazol $(49)^{80}$, desenhouse o sistema de 14 elétrons- $\pi$ pirazolo[3,4- $b]$ tieno[2,3- $d$ ]piridina $(50)^{81}$. Finalmente, por simplificação molecular o derivado tiofênico (51, d, Esquema 24) $)^{82}$ e isósteros mais simples (52, e, Esquema 24),

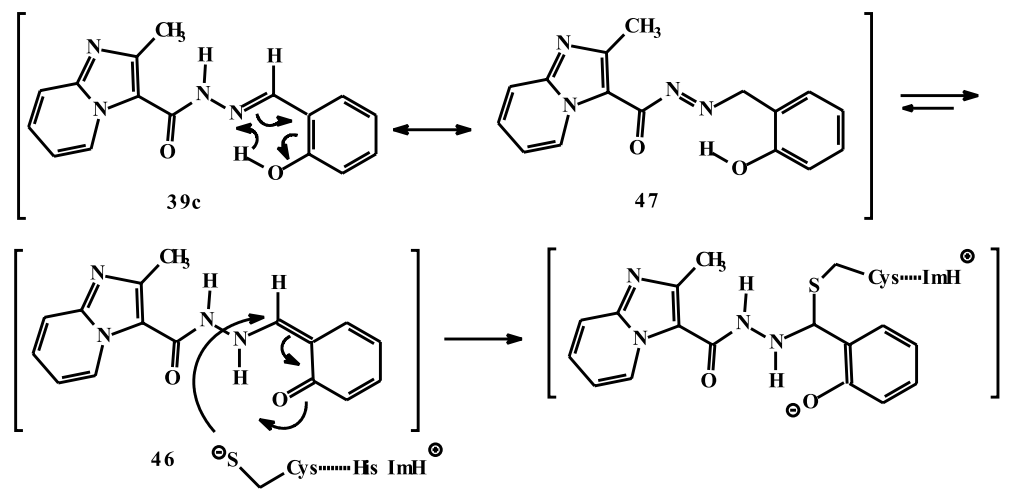<smiles>COCC(c1ccccc1-c1ccccc1)N([TlH])NC(=O)c1c(C)nc2ccccn12</smiles>

Aduto irreversível 
com apenas 6 elétrons- $\pi{ }^{82}$ foram sintetizados, de forma a complementar a diversidade molecular desta classe de derivados NAH bioativos.

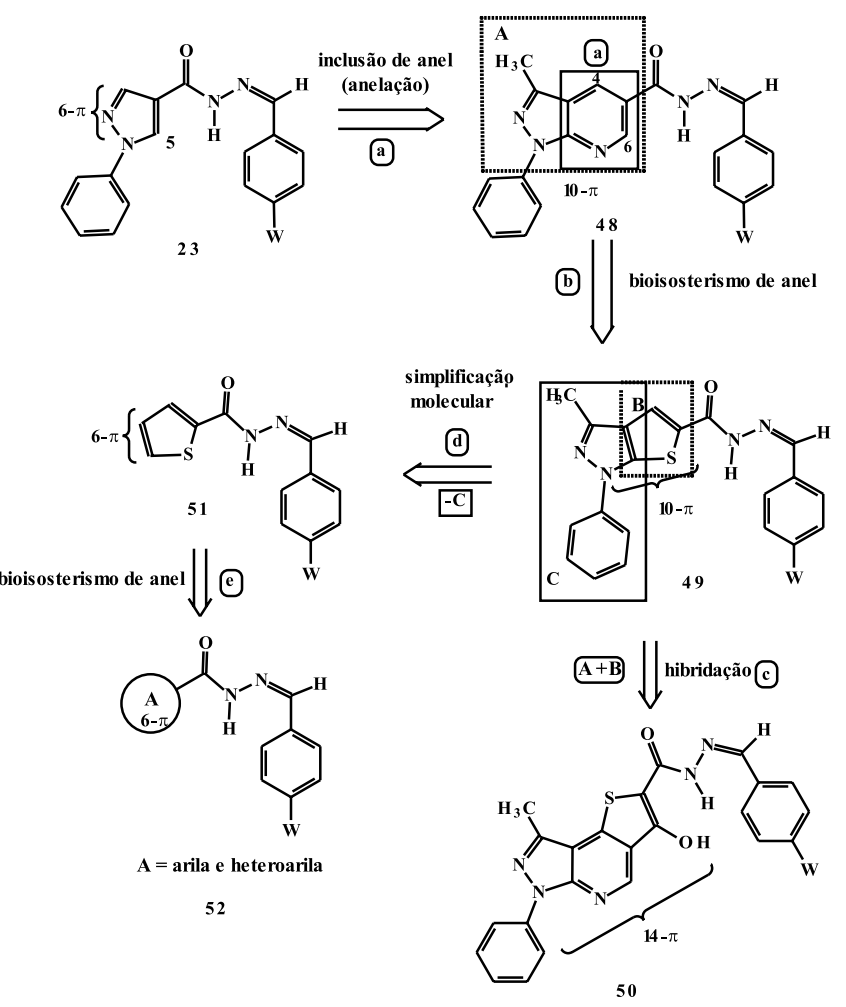

Esquema 24

\section{SÉRIE DE DERIVADOS NAH N-FENILPIRAZOLO[3,4-b]-5- PIRIDÍNICOS (48)}

A nova série de derivados NAH contendo 10 elétrons- $\pi$ no anel acil- aromático, mas ainda possuindo o grupo $N$-fenila do protótipo original (23), está representada pelo sistema pirazolo[3,4-b]piridina (48). ${ }^{79,83}$ Nesta família de compostos, manteve-se uma relação-meta da função NAH com o nitrogênio do anel acil-heteroarila, a exemplo do que ocorria na série pirazólica-protótipo (23), regio-localizando a cadeia farmacofórica NAH em C-5. Ademais, o mesmo padrão de substituição em orto com dois átomos de hidrogênio mimetiza, simultaneamente, o padrão estrutural e conformacional observado na série protótipo (23), permitindo que se avaliem os efeitos da hidrofobicidade do novo sistema (48) nas atividades investigadas.

A síntese destes derivados 48 está ilustrada no Esquema 25.79, 83

A reação de Michael entre etoximetilenomalonato de etila (EMME) e a $N$-fenil-3-metil-5-aminopirazol (53) levou ao aduto de adição 4-hidroxilado (54), que foi tratado com oxicloreto de fósforo, fornecendo 55. Hidrogenólise de 55 produziu o éster 56, que, após hidrazinólise com hidrato de hidrazina, produziu a hidrazida 57. Condensação catalisada por ácido de 57 com os respectivos aldeídos originou a nova série desejada 48 (Esquema 25). ${ }^{79}$ Quando o cloro-éster 55 foi tratado nas condições de hidrazinólise obteve-se, quantitativamente, o derivado tricíclico 58 (Esquema 26). ${ }^{79}$

Uma forte absorção no espectro IV em $3200 \mathrm{~cm}-1$ (N-H) associada à presença de sinais simples nos espectros de RMN ${ }^{1} \mathrm{H}$ e ${ }^{13} \mathrm{C}$ em $\delta$ 8,5-9,0 e d144,2-148,5 (C-H imínico), respectivamente, permitiu evidenciar a predominância da forma tautomérica eno-hidrazônica e da configuração $\mathrm{Z}$ para a insaturação na série de derivados 48 . Ademais, estudos de modelagem molecular com uma série de compos-
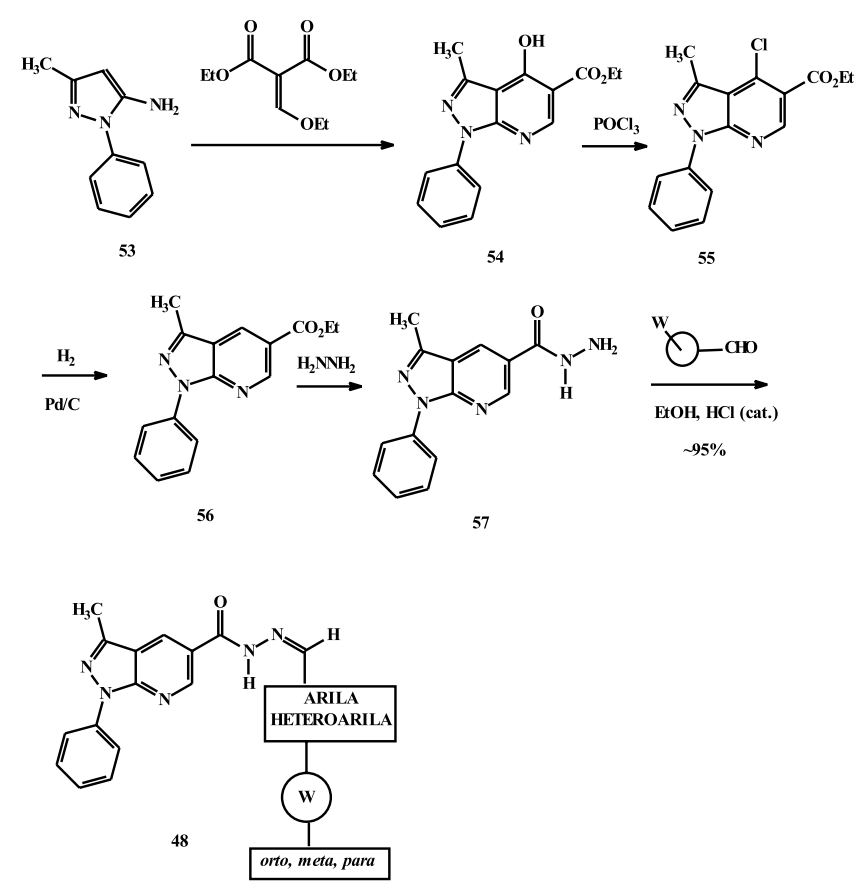

Esquema 25
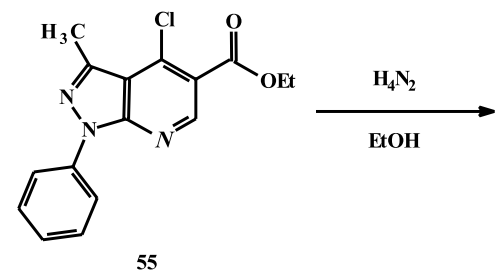

Esquema 26 tos similares mostraram uma diferença de $c a .3 \mathrm{Kcal} / \mathrm{mol}$ em favor deste diastêroisômero ${ }^{84}$.

A investigação das propriedades farmacológicas desta série (48) indicou para o derivado não-substituído LASSBio-59 (48a, W=H, Esquema 24) atividade analgésica equipotente $(51 \%, 93 \mu \mathrm{mol} / \mathrm{kg})$ à dipirona usada como padrão. ${ }^{79}, 83$

Estudos preliminares sobre a relação quantitativa entre a estrutura química e a atividade farmacológica (QSAR) realizados para a série de derivados pirazolo-piridínicos 48 sugeriram a importância dos fatores lipofílicos dos substituintes na subunidade arila da função hidrazônica para a atividade analgésica apresentada por estes deriva$\operatorname{dos}^{79}$ e permitiram identificar uma nova relação bioisostérica entre os anéis pirazol e pirazolo[3,4-b]piridina.

\section{SÉRIE COM 10 E 14 ELÉTRONS- $\pi$ : TIENO[2,3-c]PIRAZOL (49) E PIRAZOLO[3,4-b]TIENO[2,3-d]PIRIDINA (50)}

Conforme planejado inicialmente (Esquema 24) investigamos, em seguida, o efeito da hidrofobicidade do sistema de 10 elétrons- $\pi$ efetuando a troca isostérica do anel piridínico de (48) por um núcleo tiofênico, levando aos derivados NAH com o sistema tieno[2,3c]pirazol (49). ${ }^{80}$

A síntese destes derivados está ilustrada no Esquema $27 .{ }^{80}$

A partir de $N$-fenilpirazolona (59) realizou-se a reação com o complexo de Vilsmeier-Haack logrando-se obter, em uma única etapa, o cloro-aldeído pirazólico (60) em bons rendimentos. Este intermedi- 


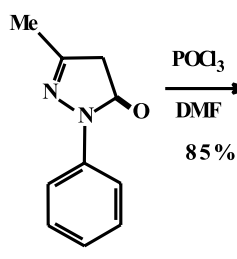

59

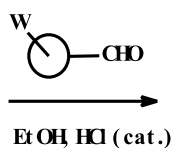<smiles>Cc1nn(-c2ccccc2)c(Cl)c1O</smiles>

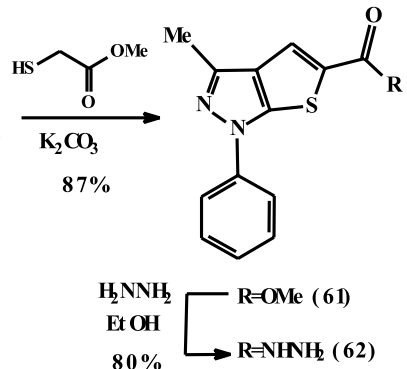

60

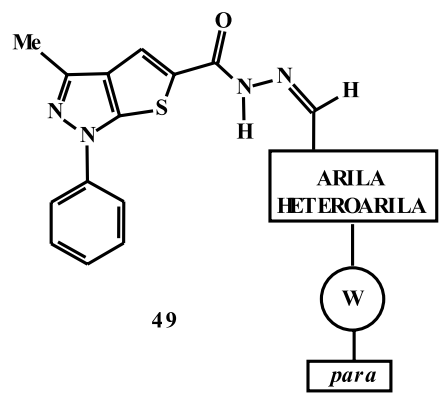

Esquema 27

ário (60), corretamente funcionalizado, permitiu efetuar-se, por tratamento com o ânion do tioglicolato de metila, em condições padronizadas, a construção do sistema bicíclico tieno[2,3-c]pirazólico (61), em processo one-pot. Este compreende uma reação de substituição nucleofílica aromática e subseqüente ciclização do tipo Claisen, in situ. ${ }^{85}$ Finalmente, hidrazinólise do éster (61) com hidrato de hidrazina produziu a hidrazida (62), que, por condensação catalisada por ácido, com os aldeídos adequados, levou à obtenção dos derivados da série 49, em bons rendimentos globais.

Os derivados NAH tricíclicos com 14 elétrons- $\pi$ no sistema pirazolo[3,4- $b]$ tieno[2,3- $d]$ piridina (50) foram sintetizados analogamente conforme ilustra o Esquema 28, a partir do cloro-éster (55), empregando-se a mesma estratégia one-pot ${ }^{81}$.

Os novos derivados NAH (50) foram estruturalmente caracterizados, sendo o diastêreoisomero-Z $Z$ predominante, exceto para o composto 50 no qual $\mathbf{W}=$ OMe (Esquema 24), que se mostrou como mistura Z/E. Nesta série de derivados NAH (50) investigamos o efeito-orto da hidroxila vizinha à cadeia farmacofórica, tendo sido pos- sível evidenciar, por estudos de modelagem molecular empregando o Hamiltoniano AM1 do programa MOPAC 7.0, que devido à formação de ligação-H intramolecular o confôrmero $S$-cis predominava (e.g. 50a). ${ }^{81}$

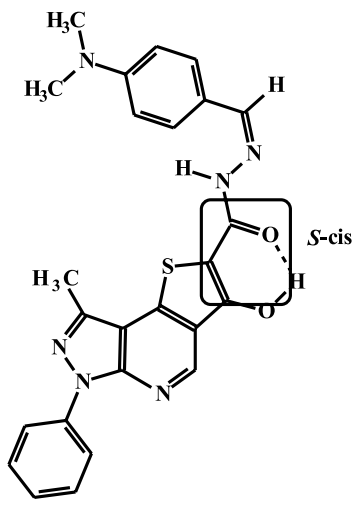

$50 \mathrm{a}$

Estes compostos (50) mostraram-se predominantemente antiagregantes plaquetários inibindo a agregação induzida pelo fator de agregação plaquetária (PAF) em torno de $30 \%$ na concentração de $100 \mu \mathrm{M}$. Quando ensaiados no modelo das contorções induzidas em camundongos, o derivado para-dimetilaminofenila (50a) foi o mais ativo, apresentando atividade relativa à dipirona de 0,84 na dose de $100 \mu \mathrm{mol} / \mathrm{kg}^{81}$

\section{N-ACILIDRAZONAS COM 6 ELÉTRONS- $\pi$ (52) NA UNIDADE ACILA}

Conforme ilustrado no Esquema 24, restava-nos investigar, ainda, a contribuição de anéis com 6 elétrons- $\pi .^{82}$ Por simplificação molecular da série (49), excluindo-se a subunidade $N$-fenilpirazol (C, Esquema 24), a série tiofênica (51) foi identificada e diversas novas séries isostéricas (52, Esquema 29) foram sintetizadas.

A síntese destas séries de derivados NAH (52a-j, Esquema 29) se fundamentou na mesma metodologia anteriormente descrita, a partir do éster corrrespondente efetuando-se as interconversões funcionais necessárias. ${ }^{82}$

Como todas as séries de derivados NAH até então estudadas apresentavam a função NAH diretamente ligada ao sistema aromático,<smiles>CCCC(=O)OCc1cnc2c(c(C)nn2-c2ccccc2)c1Cl</smiles><smiles>CCCC(=O)c1sc2c(cnc3c2c(C)nn3-c2ccccc2)c1O</smiles><smiles>Cc1nn(-c2ccccc2)c2ncc3c(O)c(C(=O)NN)sc3c12</smiles>

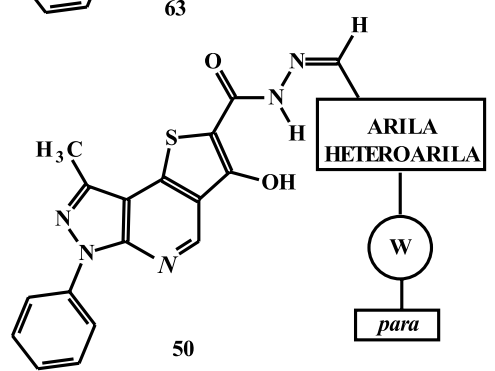




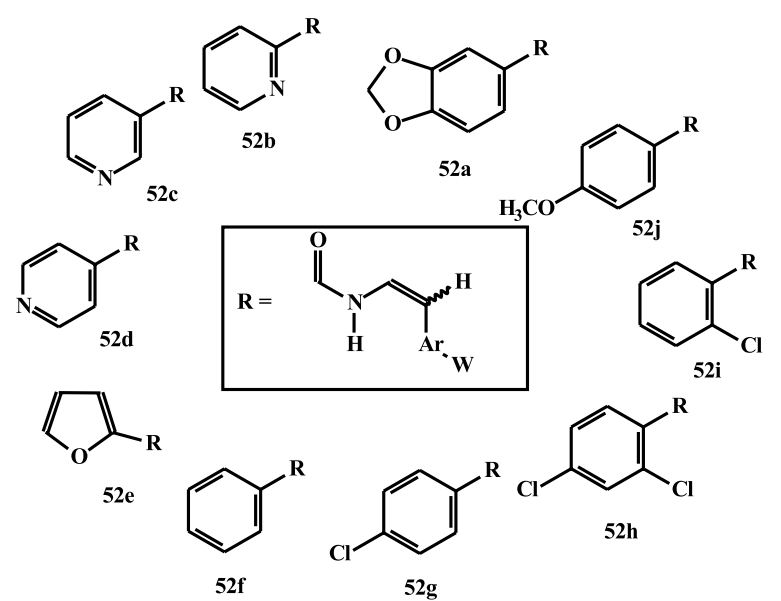

Esquema 29

decidiu-se investigar o efeito da introdução de uma unidade espaçadora entre o grupamento farmacofórico e o anel aromático (Esquema 30), obtendo-se análogos conformacionalmente mais flexíveis, com unidade espaçadora de dois átomos de carbono $\left(\mathrm{C}_{2}\right)$, saturada $\mathrm{e}$ insaturada $(65 a, b) .^{82}$
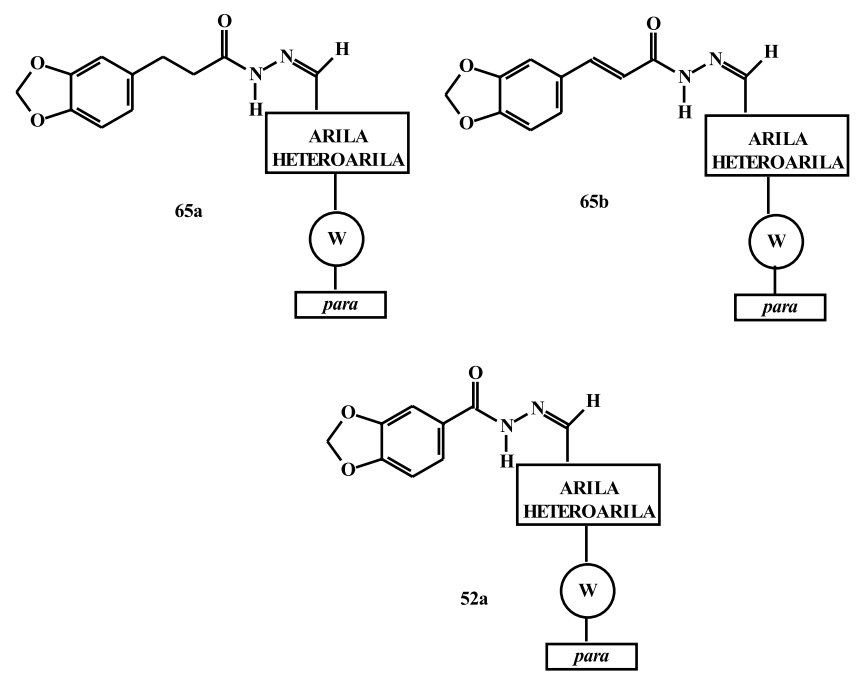

Esquema 30
Os derivados (65a) foram sintetizados por hidrazinólise do éster (66a), preparados segundo o Esquema 31, seguido de condensação ácido catalisada com os aldeídos adequados ${ }^{82} \mathrm{~A}$ única exceção foi a série insaturada (65b), na qual a hidrazida foi preparada a partir do respectivo cloreto de ácido (67), uma vez que não se logrou obter a quimiosseletividade desejada quando se tratou o éster correspondente (66b) nas condições de hidrazinólise. ${ }^{86}$ Nestas condições, observouse a competição da reação de adição do tipo Michael. O cloreto de ácido (67), por sua vez, foi preparado condensando o piperonal (68), oriundo do safrol (8), por condensação com ácido malônico nas condições de Knoevenagel-Doebner, originando o éster acrílico correspondente (66b), que, tratado com cloreto de tionila, forneceu o cloreto de ácido desejado (67), cuja configuração- $E$ da ligação dupla $\mathbf{C}=\mathbf{C}$ foi identificada por RMN ${ }^{1} \mathrm{H}^{87} \mathrm{~A}$ oxidação do piperonal (68) nas condições de Yamada (iodo, hidróxido de potássio em metanol ${ }^{88}$ foi o método de preparação do éster precursor da série (52a). ${ }^{86}$

A influência do anel 1,3-benzodioxólico presente nas séries 52a e 65 na atividade analgésica observada para estes compostos foi investigada pela avaliação das séries isostéricas $52 \mathrm{~b}$-j descritas no Esquema 29.

Da mesma maneira que para com as séries de derivados NAH anteriores, estas também tiveram a configuração da dupla ligação imínica determinada ${ }^{86,87}$ e confirmada pelo estudo da estabilidade relativa na formação dos dois possíveis diastereoisômeros por modelagem molecular, usando o Hamiltoniano AM1 do programa MOPAC, versão $7,0{ }^{89}$

Cabe ressaltar que nos derivados com a unidade espaçadora $\mathrm{C}_{2}$ saturada e insaturada, arilideno 3,4-metilenodioxifenilpropionilidrazina (65a) e arilideno 3,4-metilenodioxifenilacriloilidrazina (65b), respectivamente, a configuração da ligação $\mathbf{C}=\mathbf{N}$ foi identificada como sendo distinta das séries em que a unidade acila está diretamente conjugada com o anel aromático ou heteroaromático. Nestes compostos, a configuração- $E$ predomina. ${ }^{82}$ Estes resultados sugerem o envolvimento de fatores estereo-eletrônicos, em estudo no momento, na diastereosseletividade da etapa de condensação catalisada por ácido da hidrazida com carbonilas aldeídicas. ${ }^{82}$

Os compostos foram ensaiados nos protocolos clássicos, permitindo identificar-se os derivados (52a), da série benzodioxol, com o substitinte Ar-W, sendo, respectivamente, 2-piridinil (52aa), 3piridinil (52ab) e para-dimetilaminofenila (LASSBio-125, 52ac) como promissores protótipos de agentes analgésicos periféricos reduzindo as contorções induzidas em camundongos, quando administrados por via oral na concentração $100 \mu \mathrm{mol} / \mathrm{kg}$, em 54,7, 51,8 e

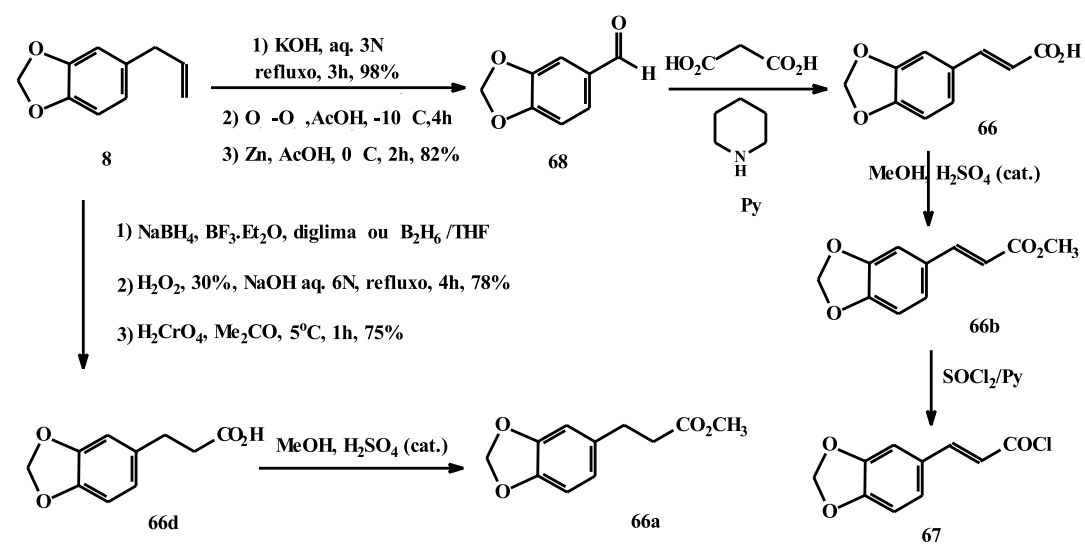

Esquema 31 
$51,2 \%$, respectivamente, o que representa um índice de potência 1,5 relativo à dipirona ${ }^{82}$ Estes resultados reforçam o cárater farmacofórico também do substituinte imínico para-dimetilaminofenila na ação analgésica. Em termo de comparação, o análogo não-substituído correspondente, LASSBio-123 (52ad) apresentou-se menos potente (41\%), quando administrado pela mesma via e nas mesmas concentrações. ${ }^{82}$

A natureza periférica deste efeito analgésico foi confirmada quando se investigou uma possível ação central, dos derivados mais ativos, no ensaio da placa-quente (hot-plate), empregando-se morfina como padrão. ${ }^{82}$

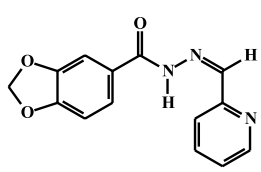

52aa

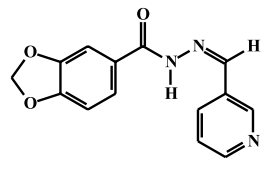

52ab

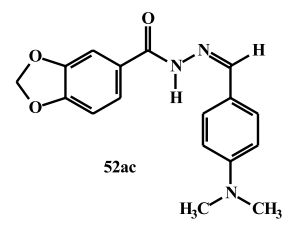

A bis-homologação, resultante da introdução da unidade espaçadora $\mathrm{C}_{2}$, correspondendo aos derivados arilideno 3,4metilenodioxifenilpropionilidrazina (65a), mais flexíveis, potencializou a atividade analgésica do derivado paradimetilaminofenilado, conforme ilustraram os resultados do composto LASSBio-131 (65aa), que reduziu em $67,1 \%$ as contorções induzidas em camundongos, quando administrado por via oral na dose de $100 \mu \mathrm{mol} / \mathrm{kg} .{ }^{82}$ Entretanto, este efeito de potencialização da atividade analgésica, pela flexibilização conformacional, somente se mostrou eficaz nos derivados possuindo o grupamento paradimetilaminofenila, pois o derivado não substituido LASSBio-359 (65ab) mostrou-se menos ativo. ${ }^{82}$ Outrossim, na série de isósteros piridínicos, orto-, meta- e para- (52b, 52c, 52d) a influência do espaçador $\mathrm{C}_{2}$ também não se verificou. ${ }^{82}$

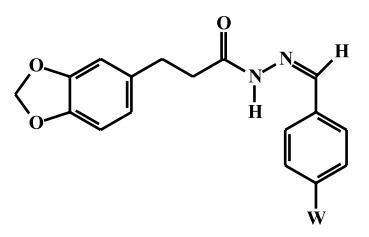

$65 \mathrm{aa} W=\mathrm{NMe}_{2}$

65ab $W=H$

A contribuição da unidade 3,4-benzodioxol da série 52a para a atividade analgésica foi investigada, também, quando se confrontou a atividade analgésica dos derivados arilideno benzoilidrazina (52f) com o correspondente análogo benzodioxólico (52ac). Esta simplificação molecular mostrou-se deletéria para a atividade analgésica como evidenciado pelo derivado LASSBio-352 (52fa), que, praticamente, não apresentou atividade quando ensaiado nas mesmas concentrações que $52 \mathrm{ac}^{82}$<smiles>CN(C)c1ccc(/C=N/NC(=O)c2ccccc2)cc1</smiles>

Estes resultados reafirmam a contribuição farmacofórica do grupamento para-dimetiaminofenila da subunidade imínica para a atividade analgésica e indicam que seu caráter doador de ligação-H é um fator estrutural provavelmente relevante para esta atividade. Ade- mais, indicaram, ainda, que o biorreceptor envolvido não reconhece substituintes aceptores de ligação-H no anel acil-aromático, ao menos quando na posição para- do anel fenílico. Todavia, a ausência de atividade analgésica significativa para o composto tiofênico (51, $\mathbf{W}=\mathrm{NMe}_{2}$, Esquema 24) sugere que a presença da ponte 3,4benzodioxol, aceptora de ligação-H, possa representar, nesta série de compostos com 6 elétrons- $\pi$ (52), um requisito estrutural acessório à atividade analgésica. Isto se verifica desde que esteja conjugado a outros fatores estruturais, como sugerem os resultados obtidos com o LASSBio-575 (52j, W = $\mathrm{NMe}_{2}$, Esquema 24), que, embora possua o substituinte para-metoxifenila na subunidade acila, não apresentou atividade analgésica. ${ }^{82}$

Curiosamente, a presença da insaturação na unidade espaçadora $\mathrm{C}_{2}$, levando à série viníloga $(65 \mathrm{~b})$, provocou redução drástica na atividade analgésica, conforme ilustrado pelo LASSBio-353 (65b, W = para $-\mathrm{C}_{6} \mathrm{H}_{4} \mathrm{NMe}_{2}$ ), que se mostrou menos ativo que o derivado saturado correspondente (65aa, LASSBio-131), o mais ativo nesta série. ${ }^{82}$ Estes resultados parecem indicar que a flexibilidade conformacional da cadeia NAH é um fator estrutural que potencializa esta atividade. Ademais, quando a unidade espaçadora mimetizou uma ligação peptídica (e.g. 73, 74), na qual podem ocorrer ligações$\mathrm{H}$ intramoleculares capazes de orientarem conformacionalmente a cadeia que possui o principal grupamento farmacofórico, também não se observou atividade analgésica digna de nota.<smiles>O=C(NCC(=O)c1ccccc1)N/N=C/I</smiles>

73<smiles>O=C(CNC(=O)c1ccc2c(c1)OCO2)N/N=C\[Tl]</smiles>

74
Com o intuito de se elucidar a natureza das interações envolvendo os substutintes do anel acil-aromático desta classe de derivados NAH bioativos, com os biorreceptores nociceptivos, decidiu-se sintetizar os derivados cloro-subtituídos representados pelas séries ortoclorada (52i), para-clorada (52g) e orto-para-diclorada (52h) (Esquema 29$)^{90}$. A introdução dos átomos de cloro no anel fenílico, praticamente, exclui a possibilidade de interações por ligações- $\mathrm{H}$ com o sítio receptor, conforme sugerido pela atividade dos derivados com o sistema benzodioxol (52a).

Os resultados dos bioensaios de analgesia obtidos com estas séries de NAH cloradas (52ghi) indicaram que a introdução de átomos de cloro no anel aromático, independente do padrão de substituição do anel aromático do término imínico, leva à perda da atividade analgésica. ${ }^{91}$ Estes resultados, embora negativos em termos de atividade analgésica, contribuíram significativamente para compreender-se que ao nível do anel acil-aromático deste compostos NAH, o reconhecimento molecular pelos receptores nociceptivos envolvidos podem operar por ligações-H regiosseletivas ou explorando propriedades redox do padrão de substituição, quando fenil-oxigenado.

Visando compreender os aspectos conformacionais envolvidos na potencialização da atividade analgésica observada com a introdução da unidade espaçadora $\mathrm{C}_{2}$, saturada, decidimos introduzir uma restrição conformacional na cadeia $\mathrm{NAH}$, mas mantendo a natureza $\mathrm{sp}^{3}$ de sua unidade espaçadora. Este raciocínio nos conduziu à série isocromanilacetilarilidrazonas (75) (Esquema 32), ${ }^{92}$ cujos ácidos correspondentes (76) já haviam sido identificados como antiinflamatórios ${ }^{93}$. Estes derivados (75) foram sintetizados utilizando-se o éster (76a), obtido a partir do safrol (8), conforme ilustrado no Esquema $32 .{ }^{92}$

Os resultados obtidos na avaliação das propriedades analgésicas destes compostos (75) indicaram a maior atividade analgésica novamente para o derivado para-dimetilaminofenila substituído LASSBio- 

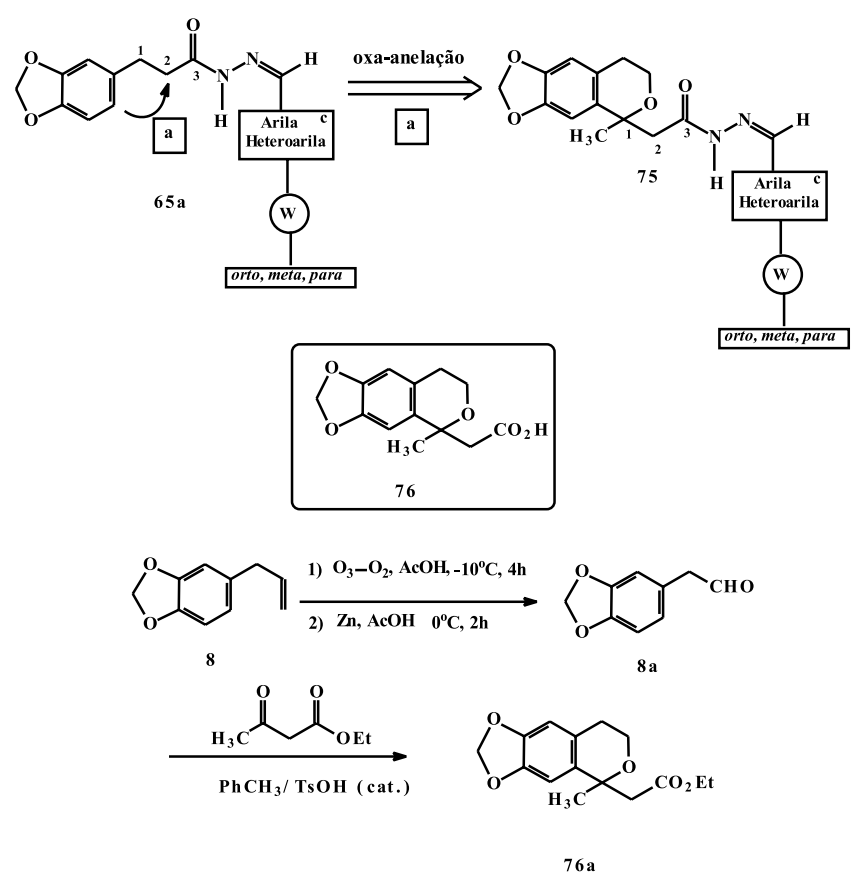

Esquema 32

143 (75a), que reduziu as contorções induzidas em camundongos na ordem de 53,3\%, quando administrado p.o. na concentração de $100 \mathrm{mmol} / \mathrm{kg} .{ }^{92}$

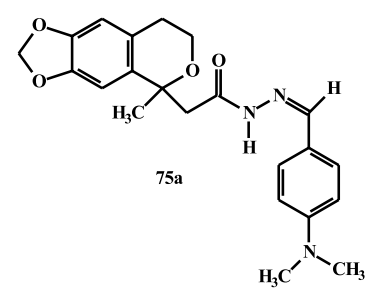

Vale destacar que nesta série, observou-se a presença majoritária do diasterêoisomero $(E)$ ao nível da ligação imínica ${ }^{92}$. Devido à existência do centro estereogênico em C-1 do anel isocromânico e a presença da insaturação imínica nesta série de derivados NAH realizaram-se cuidadosos estudos de RMN da mistura diastereoisomérica de cada composto (75), permitindo evidenciar a relação de 70:30 em favor do diastereoisômero- $E{ }^{87}$

Os resultados farmacológicos obtidos com o derivado (75a) sugerem que a restrição conformacional introduzida pelo anel isocromânico nesta série pode estar mimetizando a conformação bioativa do composto (65ac), possuindo a unidade espaçadora $\mathrm{C}_{2}$.

Finalmente, nossos estudos visando à compreensão dos fatores estruturais envolvidos na resposta analgésica desta série de derivados NAH conduziram-nos a investigar a contribuição da carbonila da função NAH, capaz de interagir com os receptores nociceptivos por meio de ligações-H, atuando como sítio aceptor-H. Desta forma, decidiu-se efetuar a troca isostérica funcional da carbonila dos derivados NAH por um grupamento sulfona,,${ }^{94}$ de forma a favorecer as possibilidades de interações aceptoras de ligações-H (Esquema 33). Desta forma, foram sintetizados os isósteros $N$-sulfonilidrazônicos (SAH) (77 e 78)..$^{94}$ Os resultados dos ensaios farmacológicos com a série (77) indicaram perfil analgésico similar aos derivados NAH correspondentes, ${ }^{95}$ confirmando, de um lado, a validade da troca isostérica realizada como estratégia de modificação molecular nesta classe, e de outro, reiterando a possibilidade de interação desta funcionalidade com os receptores mediante ligações-H.

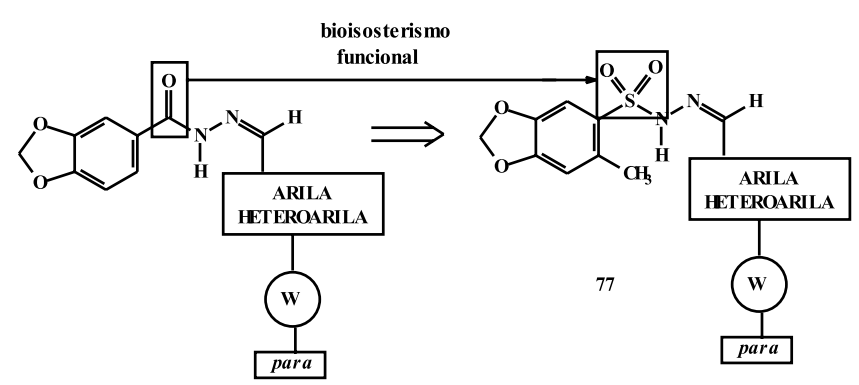

Esquema 33

\section{SÉRIE IMIDAZÓLICA, NOVA CLASSE DE COMPOSTOS ANALGÉSICOS DESCOBERTA POR OTIMIZACÃO}

Face aos resultados até então obtidos, decidimos concentrar esforços no estudo da atividade analgésica desta classe de derivados $\mathrm{NAH}$, investigando a eventual potencialização da atividade analgésica, identificada nesta classe, pela introdução na subunidade acilarila de um sistema heteroaromático com 6 elétrons- $\pi$, capaz de interagir por ligações-H com os biorreceptores envolvidos nas resposta algésica. Desta forma, por simplificação molecular da série imidazo[1,2-a]piridina (39) com propriedades analgésicas previamente identificadas, originou-se a nova série $N$-acil-5-metil-4imidazolilidrazona (79) (Esquema 34). ${ }^{96}$
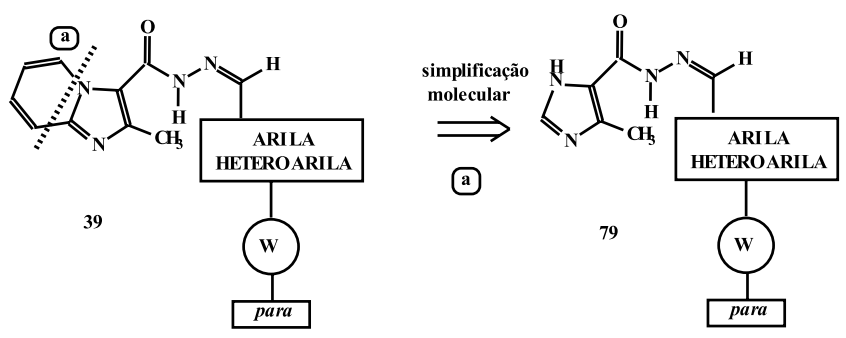

\section{Esquema 34}

Esta nova série (79) apresenta como principal característica estrutural elevado índice de similaridade com a série protótipo (39), desde a presença do substituinte metila no anel heterocíclico, também orto-orientado em relação à cadeia farmacofórica NAH. Nesta série (79) a presença deste grupamento orto-metila se fazia necessária para "fixar" as formas protoméricas possíveis nos sistemas imidazólicos (Esquema 35), facilitando o estudo da relação estrutura-atividade analgésica. Ademais, face aos dados relativos aos efeitos analgésicos máximos das séries anteriomente investigadas, o substituinte $\mathbf{W}$ do anel fenílico da subunidade imínica foi definido como para-orientado.<smiles></smiles><smiles>Cc1nc[nH]c1C(=O)N/N=C\c1ccc([AlH2])cc1</smiles>

Esquema 35 
A síntese destes derivados (79) está ilustrada no Esquema 36. ${ }^{96}$

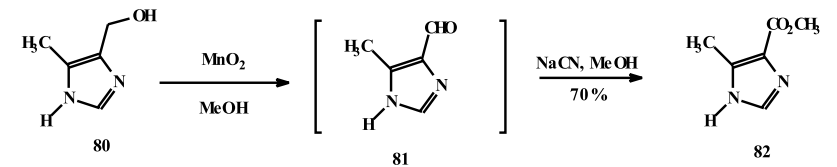

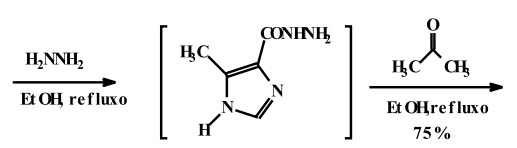

83<smiles>CC(C)=CN(I)C(=O)C1=C(Br)NCN1</smiles>

84

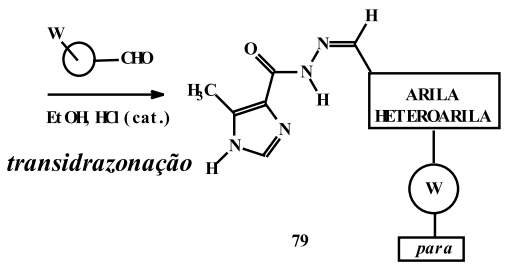

Esquema 36

A oxidação do álcool imidazólico (80) com dióxido de manganês em metanol levou ao aldeído correspondente (81). Oxidação empregando cianeto de sódio em metanol ${ }^{97}$ conduziu ao éster metílico 82 , precursor clássico das hidrazidas necessárias à construção da unidade NAH. O éster 82 pôde ser convertido à hidrazida correspondente, nas condições de hidrazinólise classicamente empregadas ao longo deste trabalho, conforme evidenciado por análise cromatográfica da mistura reacional. Infelizmente, a despeito das inúmeras tentativas realizadas no sentido de se isolar, classicamente, este intermediáriochave (83), não se logrou sucesso, tendo esta substância se mostrado extremamente hidrossolúvel. Face a este resultado, inesperado, conseguiu-se superar esta limitação experimental efetuando-se o tratamento da mistura reacional contendo 83, com excesso de acetona, à temperatura ambiente. Este procedimento levou à formação, in situ, da hidrazona correspondente (84), que precipitou no meio reacional como um sólido amarelo, estável. Nesta etapa, para a obtenção das diversas NAH desejadas, a hidrazona da acetona (84) foi submetida à reação de transidrazonação com os aldeídos desejados, fornecendo os derivados finais da nova série 79, em bons rendimentos globais (Esquema 36)..$^{96}$

Estudos realizados por mecânica molecular e métodos semiempíricos para confirmação da configuração da ligação dupla $\mathbf{C}=\mathbf{N}$ da função hidrazona e do protômero de maior estabilidade nesta série 79 , indicaram que o protômero $N-1$ era mais estável que o protômero $N-3$, devido, provavelmente, à proximidade do grupo metila em $\mathbf{C - 5}{ }^{98}$.

Análise espectroscópica, cuidadosa, por RMN de ${ }^{1} \mathrm{H}$ e ${ }^{13} \mathrm{C}$ e IV, dos compostos 79 permitiu evidenciar a formação diastereosseletiva do isômero- $Z$, predominância da forma eno-hidrazona e do tautômero $N-1$, conforme antecipado pelos cálculos téoricos. ${ }^{96}$

As atividades antiinflamatórias foram investigadas, in vivo, nos ensaios classicamente empregados no laboratório, evidenciando, no ensaio do edema de pata induzido por carragenina, uma inibição significativa, em torno de $56,4 \%$, para o composto (79a) com o substituinte para-bromofenila no grupo imínico terminal e $40 \%$ para o análogo para-dimetilaminofenila (79b), na dose de $100 \mu \mathrm{mol} / \mathrm{kg}$. Ademais, o mesmo derivado para-bromofenilado (LASSBio-349, 79a) reduziu em $61,7 \%$ as contorções induzidas em camundongos na concentração de $50 \mu \mathrm{mol} / \mathrm{kg}$, enquanto que o derivado para-dimetilaminofenilado (79b) correspondente mostrou-se 58\% ativo na concentração de 100 $\mu \mathrm{mol} / \mathrm{kg} .{ }^{99}$ Nesta série de derivados NAH (79) foi obtido o composto com o substituinte aromático da subunidade imínica contendo o grupo 3,5-di-tert-butil-4-hidroxifenila (79c), que apresentou um valor de $\mathrm{ED}_{50}$ de $18,75 \mu \mathrm{mol} / \mathrm{kg}$, sendo o analgésico mais potente obtido durante estes estudos. Este representa um autêntico novo protótipo, ativo, inclusive, no modelo farmacológico da formalina que remete aos mediadores prostanóides. ${ }^{100}$<smiles>Cc1[nH]cnc1C(=O)N/N=C\c1cc(C(C)(C)C)c(O)c(C(C)(C)C)c1</smiles>

LASSBio-349 (79c)

$\mathrm{ED}_{50} 18,75 \mu \mathrm{mol} / \mathrm{kg}$

Estes resultados coroaram os esforços realizados no estudo desta classe de derivados bioativos, visto que a série de compostos NAH imidazólicos (79) representa uma nova classe de potentes candidatos a agentes analgésicos periféricos, de fácil acesso sintético. A maior potência do derivado (79c), possuindo um grupamento com propriedades redox particulares, sugere que esta substância possa estar atuando por mecanismo no qual as características redox sejam farmacoforicamente relevantes. Tal mecanismo está sendo investigado no laboratório no momento.

Em resumo, face aos resultados obtidos nestes estudos sobre a relação-estrutura e atividade nas diferentes séries destes novos derivados NAH bioativos, esquematizamos na Figura 5 as possíveis interações de suas subunidades estruturais com os receptores hipotéticos, nociceptores ou não, envolvidos nas respostas farmacológicas identificadas nesta nova classe de compostos-protótipos.

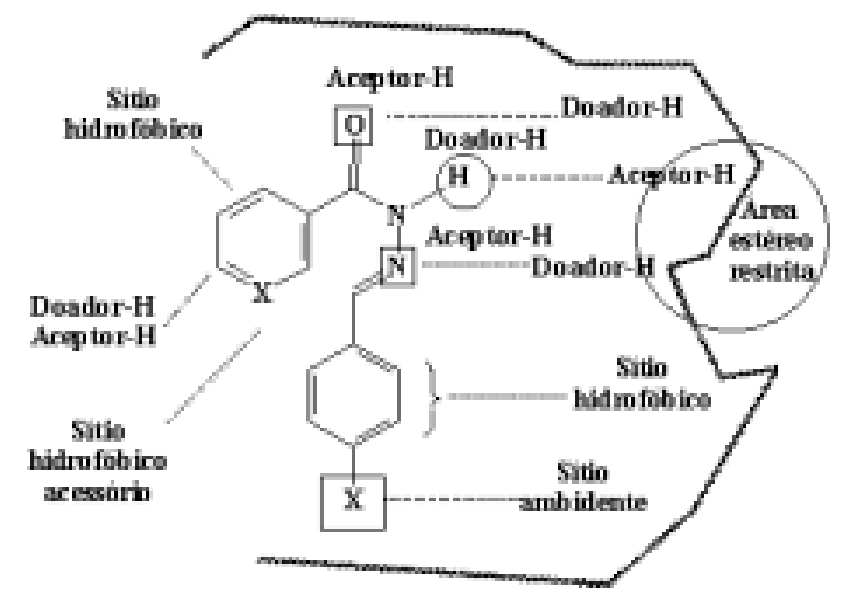

Figura 5. Possiveis interações dos derivados NAH com os receptores hipotéticos.

\section{CONSIDERAÇÕES FINAIS}

Face ao sucesso logrado com a descoberta do novo candidato a protótipo de agente analgésico, representado pelo composto LASSSBio-349 (79c), novas variações estruturais foram recentemente introduzidas na subunidade acil-aromática. Estas encontram-se ilustradas no Esquema 37, combinando-se com o padrão da subunidade imínica, representadas pelas novas séries (85-94), que estão sendo, algumas sintetizadas e outras avaliadas, farmacologicamente, no laboratório no momento. ${ }^{101-104}$ 


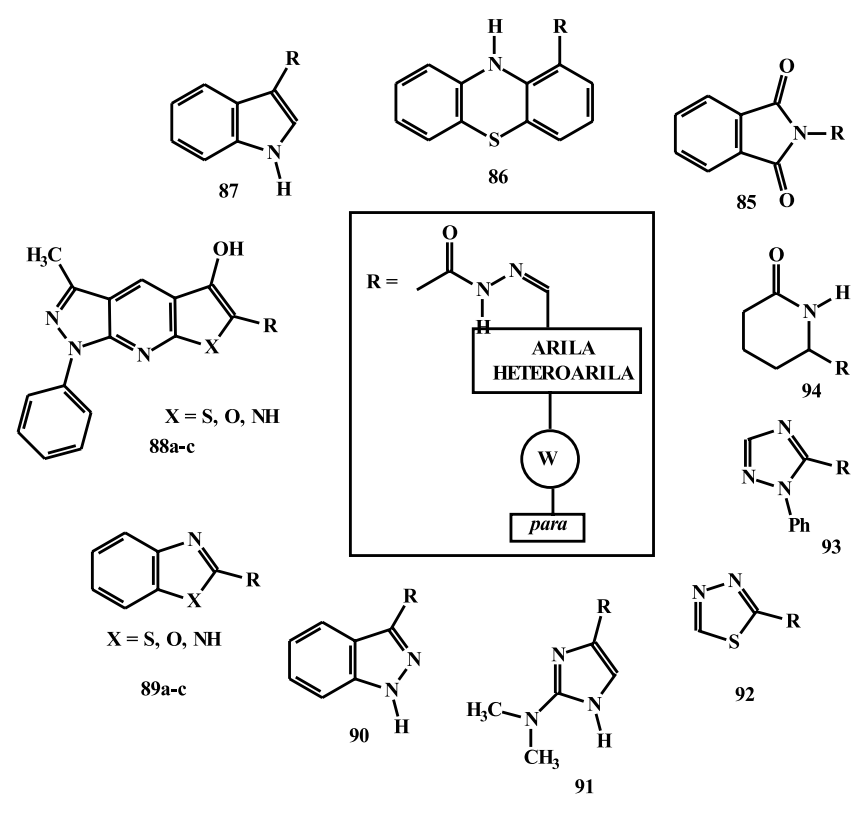

Esquema 37

A título de ilustração, os resultados farmacológicos disponíveis para a série indólica (87) (Esquema 37) demonstraram que os derivados contendo o grupo para-dimetilaminofenila (LASSBio-509, 87a), para-bromofenila (LASSBio-510, 87b) e fenila (LASSBio$550,87 \mathrm{c}$ ) na subunidade imínica, mostraram-se significativamente ativos no teste de analgesia periférica, reduzindo, expressivamente, as contorções abdominais induzidas por ácido acético, em camundongos, na ordem de 50,5, 43,7 e 38,8\%, respectivamente, na dose de $100 \mathrm{mmol} / \mathrm{kg} .{ }^{105}$

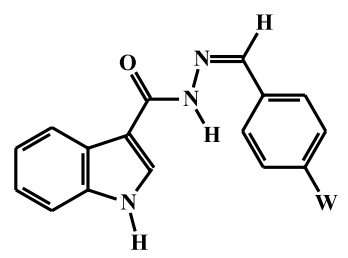

$$
\begin{aligned}
& 87 \mathbf{a} W=\mathrm{NMe}_{2} \\
& 87 \mathrm{~b} \mathrm{~W}=\mathbf{B r} \\
& 87 \mathrm{c} \mathrm{W}=\mathbf{H}
\end{aligned}
$$

Cabe destacar que a eleição da natureza da subunidade acila nestas novas séries de derivados NAH objetivou obter-se novos compostos ativos, simultaneamente, em mais de um alvo-terapêutico envolvido na fisiopatologia da dor e da resposta inflamatória $\left(\right.$ e.g. 85) ${ }^{106}$, inclusive visando-se investigar possíveis ações centrais (e.g. 86). ${ }^{107}$

\section{CONCLUSÕES}

Neste artigo procuramos reunir alguns dos resultados dos estudos realizados no laboratório nos últimos dez anos, versando sobre a Química Medicinal de derivados $N$-acilidrazônicos bioativos, estruturalmente planejados pelo emprego de estratégias de desenho molecular, particularmente hibridação, simplificação molecular e bioisosterismo clássico, de anel e funcional, além de restrição conformacional. Estas estratégias visaram compreender a relação entre a estrutura química e as atividades antiinflamatórias, analgésicas e antitrombóticas identificadas para esta classe de derivados. Como ferramenta útil ao planejamento molecular das novas classes de compostos protótipos descobertos, empregaram-se técnicas de modelagem molecular, que se mostraram especialmente proveitosas na elucidação de seus aspectos estruturais e conformacionais, relevantes à completa compreensão da relação entre a estrutura e as atividades observadas.

Como fruto destes estudos, que permitiram a síntese de centenas de novos derivados NAH bioativos, identificou-se a contribuição farmacofórica da função $N$-acilidrazona, além de se evidenciar outras contribuições farmacofóricas distintas, específicas para as atividades analgésica e anti-agregante plaquetária. Tais contribuições representam critérios moleculares úteis para o planejamento das novas modificações estruturais a serem introduzidas nos protótipos descobertos, representando a etapa de otimização destas atividades e visando identificar os farmacóforos específicos envolvidos na "mensagem-endereço" das diferentes atividades identificadas (Esquema 37).

Outrossim, estudos das propriedades estruturais desta classe de derivados permitiram identificar o valor da constante fragmentar para a função hidrazona e caracterizar padrões espectroscópicos que permitem a determinação da configuração da ligação imínica da função $\mathrm{N}$-acilidrazona. Além disso, estes estudos evidenciaram, ainda, que a conformação $S$-cis da função NAH predomina nesta classe de compostos, que não apresentam tautomeria eno-diazo, em solução. ${ }^{108,} 109$ Ademais, identificou-se a diastereosseletividade da etapa-chave de síntese dos derivados NAH, a condensação catalisada por ácido entre hidrazidas e aldeídos aromáticos ou heteroaromáticos, que se mostrou dependente de efeitos estéreo-eletrônicos presentes na estrutura da hidrazida, objeto de investigação minuciosa no laboratório, no momento.

Várias metodologias sintéticas foram empregadas para a obtenção dos diversos ésteres, precursores das hidrazidas, intermediárioschaves na síntese dos derivados NAH descritos, que foram, por sua vez, preparados utilizando-se metodologia similar, de simples execução, baixo custo, versátil e de bons rendimentos.

Destes estudos logrou-se identificar potente agente anti-agregante plaquetário da classe das hidrazonas (17, LASSBio-316 ) com $\mathrm{IC}_{50}$ de $0,35 \mu \mathrm{mol}$ e dois compostos da classe das NAH (LASSBio-35, 23a) com $\mathrm{IC}_{50}$ de 23,7 $\mu \mathrm{mol}$, respectivamente, além de promissor agente analgésico (LASSBio-369, 79c) com $\mathrm{ED}_{50}$ de $18,75 \mu \mathrm{mol} / \mathrm{kg}$, cujo mecanismo de ação é objeto de investigação no momento. $\mathrm{O}$ derivado LASSBio-30 (23b) apresentou atraente perfil analgésico, sendo 5,2 vezes mais potente que a dipirona no ensaio de contorções abdominais induzidas pela acetilcolina ( $\mathrm{ACh}$ ) em camundongos. Ademais, o composto LASSBio-132 (11e), ensaiado no modelo de pleurisia induzida por carragenina em ratos, inibiu a migração de leucócitos e reduziu o volume de exsudato pleural em 96,6 e 93,4\%, respectivamente, em doses de $40 \mu \mathrm{mol} / \mathrm{kg}$, representando importante perfil antiedematogênico.

O derivado NAH, LASSBio-39, quando investigado ao nível central, mostrou-se ativo sobre a liberação de neurotransmissores em neurônios hipocampais de rato, provavelmente, por intervir com cátions divalentes aumentando a liberação espontânea e induzida de GABA, possivelmente, pelo bloqueio da atividade dos canais de $\mathrm{K}^{+}$, dependentes de $\mathrm{Ca}^{2+}$, ou pela inibição da desativação dos canais de $\mathrm{Na}^{+}$, dependentes de voltagem. ${ }^{110}$ Estes resultados acenam para novas aplicações terapêuticas desta classe de compostos NAH, fruto da identificação destas propriedades neuroativas. ${ }^{110}$

Finalmente, como fruto destes estudos e da identificação do envolvimento de derivados NAH com o $\mathrm{Ca}^{++}$celular, logrou-se descobrir um composto cardioativo (LASSBio-294), que atua na regulação do $\mathrm{Ca}^{2+}$ em fibras cardíacas desnudas ${ }^{111}$ e cujo efeito inotrópico e de relaxamento vascular, aliado à ausência de toxicidade 
aguda, motivaram depósito de patente como candidato a fármaco cardioativo. ${ }^{112}$

\section{AGRADECIMENTOS}

Os autores agradecem aos Professores Nuno A. Pereira, Luiz G. Paulo, Luiz F. Oliveira, François Noël, Roberto T. Sudo e Gisele Zapata-Sudo (Departamento de Farmacologia Básica e Clínica, ICCBUFRJ); Ricardo B. Alencastro, Francisco R. Aquino Neto, Jari N. Cardoso (Instituto de Química, UFRJ); Cristina Barja-Fidalgo e Iolanda M. Fierro (Departamento de Farmacologia, Instituto de Biologia, UERJ); Mário G. de Carvalho (Instituto de Química, UFRRJ); Raimundo Bráz-Filho (UENF); Mozart R. Neves (Departamento de Química Fundamental, UFPe); Vitor F. Ferreira (Instituto de Química, UFF) pela colaboração. Aos alunos de pós-graduação: E. F. R. Pereira, I. A. F. B. Silveira, M. E. Matheus, K. C. M. Silva, C. A Ormelli e P. H. O. Leda (Departamento de Farmacologia Básica e Clínica, ICCBUFRJ); L. F. C. C. Leite, Gildásio de Almeida Silva (in memoriam) e A. R. Todeschini (NPPN, UFRJ); M. R. L. Santos (Instituto de Química, UFRRJ); J. B. P. da Silva (Departamento de Química Fundamental, UFPe); M. J. F. Alvim, A. C. C. Freitas, C. C. Corrêa, L. R. S. Dias, T. M. Monteiro, N. P. Pereira, R. C. Martins, O. Soler, C. M. R. Sant'Anna, M. G. Albuquerque, A. S. Lages, E. F. Silva, N. C. Romeiro, D. R. Ifa, E. T. da Silva, A. G. M. Fraga, C. A. Câmara, L. M. Lima e P. C. Lima (Departamento de Química Orgânica, Instituto de Química, UFRJ); e aos estudantes de iniciação científica, A. M. A. S. P. Carvalho (in memoriam), S. O. Rocha, F. A. Violante, G. Barreiro, J. M. Figueredo, I. G. Ribeiro, S. C. Parrini, E. G. Amarante, H. Verli, J. Tributino e C. M. Duarte (Faculdade de Farmácia, UFRJ); A. C. B. Lima (UERJ), que contribuíram com seu aprendizado aos estudos das diferentes classes de derivados bioativos descritos neste artigo.

À FAPERJ, CNPq, CAPES, FUJB, Pronex pelo apoio financeiro e às Centrais Analíticas do NPPN-UFRJ e IQ-UFRJ pelos dados espectroscópicos.

Os autores agradecem à Editoria de Química Nova e aos assessores do artigo pelas valiosas sugestões que aprimoraram sua forma final.

\section{REFERÊNCIAS}

1. a) Kubinyi, H.; QSAR: Hansh Analysis and Related Approaches; VCH, Weinheim, 1993; p 240; b) Uma definição recente da Química Medicinal consta em: Wermuth, C-G.; In The Practice of Medicinal Chemistry; Wermuth, C-G. Ed.; Academic Press, NY, 1996; p 3; c) Barreiro, E. J.; Fraga, C. A. M.; Química Medicinal: As Bases Moleculares da Ação dos Fármacos; ArtMed Editora Ltda; Porto Alegre, RS, 2001; p 5.

2. Inter-alia: a) Wermuth, C-G.; J. Heterocycl. Chem. 1998, 35, 1091; b) Setti, E. L.; Micetich, R.; Curr. Med. Chem. 1996, 3, 317.

3. Gund, P.; Maggiora, G.; Snyder, J. P.; In Guidebook on Molecular Modeling in Drug Design; Cohen, N. C. Ed.; Academic Press, NY, 1996; p 219.

4. Lam, P. Y. S. et al.; Science 1994, 262, 380.

5. Ganellin, C. R.; In Medicinal Chemistry Principles and Practice; King, F. D. Ed.; RSC, London, 1994; p 189.

6. Barreiro, E. J.; Rev. Bras. Farm. 1991, 72, 2, 34.

7. Para exemplos, veja: Barreiro, E. J.; Fraga, C. A. M.; Química Medicinal: As Bases Moleculares da Ação dos Fármacos; ArtMed Editora Ltda; Porto Alegre, 2001.

8. Barreiro, E. J.; Silva, J. M. F.; Fraga, C. A. M. ; Quim. Nova 1996, 19, 641.

9. Bourguignon, J.J.; In The Practice of Medicinal Chemistry; Wermuth, CG. Ed.; Academic Press, NY, 1996; p 281.

10. a) Heller, A.; Koch, T.; Schmeck, J.; Ackern, K.; Drugs 1998, 55, 487; b) Higgs, G. A.; Moncada, S.; In Comprehensive Medicinal Chemistry, Vol. 2; Hansch, C.; Sammes, P.; Taylor, R. Eds.; Pergamon Press; Oxford, 1990 p 156; c) Davies, P.; Bailey, P. J.; Goldemberg, M. M.; Ford-Hutchinson, A. W.; Annu. Rev. Immunol. 1984, 2, 333.

11. Vane, J. R.; Bakhle, Y. S.; Botting, R. M.; Annu. Rev. Pharmacol. Toxicol. 1998, 38, 97.
12. Marnett, L. J.; Kalgutkar, A. S.; Curr. Opinion Chem. Biol. 1998, $2,482$. 13. Reitz, D. B.; Seibert, K.; Annu. Rep. Med. Chem. 1995, 30, 179.

14. a) Lombardino, J. G.; In Nonsteroidal Antiinflammatory Drugs; Lombardino, J. G. Ed.; John Wiley \& Sons; New York, 1985; b) Scherrer, R. A.; In Antiinflammatory Agents. Chemistry and Pharmacology; Scherrer, R. A.; Whitehouse, M. W. Eds.; Academic Press; New York, 1974.

15. Para uma revisão recente sobre inibidores seletivos de PGHS-2, veja : Lages, A. S.; Romeiro, N. C.; Fraga, C. A. M.; Barreiro, E. J.; Quim. Nova 1998, 21,761 .

16. O rofecoxib $\left(\right.$ Vioxx $\left.^{\circledR}\right)$ foi também lançado no Brasil como um fármaco antiinflamatório não-esteróide que atua como inibidor seletivo de PGHS2, representando uma segunda geração de agentes AI, veja: Wallace, J.; Chin, B.; Curr. Opinion in CPNS Investigational Drugs 1999, 1, 132.

17. $\mathrm{O}$ celecoxib (Celebra $\left.{ }^{\circledR}\right)$ pertence à classe dos sulidos, recentemente lançado no Brasil (1999) como um fármaco antiinflamatório não-esteróide que atua como inibidor seletivo de PGHS-2, representando uma segunda geração de agentes AI, veja: Wallace, J.; Chin, B.; Curr. Opinion in CPNS Investigational Drugs 1999, 1, 132 .

18. Conti, M.; Mol. Endocrinol. 2000, 14, 1317.

19. Newton, R. C.; Decicco, C. P.; J. Med. Chem. 1999, 42, 2295.

20. Hart, T.; Lamont, A.; Williams, D.; Drug Discovery Today 1998, 3, 516

21. Henderson, W. R.; Ann. Intern. Med. 1994, 121, 684.

22. Freitas, A. C. C.; Barreiro, E. J.; Rev. Bras. Farm. 1994, 75, 76.

23. a) Wenzell, S. E.; Kamada, A. K.; Ann. Pharmacother. 1996, 30, 858; b) Howard, H. R.; Exp. Opin. Ther. Patents 1997, 7, 353.

24. Barreiro, E. J.; Fraga, C. A. M.; Quim. Nova 1999, 23, 744

25. Barreiro, E. J.; Freitas, A. C. C.; Lima, M. E. F.; Fraga, C. A. M.; Silva, E. F.; Pereira, E. F. R.; Silveira, I. A. F. B.; Miranda, A. L. P.; In Organic Synthesis in Brazil, an Overview; Comasseto, J. V.; Ferreira, J. B.; Eds.; USP; São Paulo, 1994; p 251.

26. Lages, A. S.; Silva, K. C. M.; Miranda, A. L. P.; Fraga, C. A. M.; Barreiro, E. J.; Bioorg. Med. Chem. Lett. 1998, 8, 183.

27. Barreiro, E. J.; Fraga, C. A. M.; Araujo-Jr, J. X.; In Farmacognosia, da Planta ao Medicamento; Simões, C. M. O.; Schenkel, E. P.; Gosmann, G.; de Mello, J. C. P.; Ments, L. A.; Petrovick, P. R. Eds.; Editora da UFSC \& Editora Universidade/UFRGS, Florianopólis/Porto Alegre, 1999; p 123.

28. Ghiglieri-Bertez, C.; Coquelet, C.; Alazet, A.; Bonne, C.; Eur. J. Med. Chem. 1987, 22, 147.

29. Sincholle, D.; Bertez, C.; Legrand, A.; Conduzorgues, J.P.; Bonne, C.; Arzneim.-Forsch. 1985, 35, 1260.

30. Freitas, A. C. C.; Tese de Doutorado; UFRJ, Rio de Janeiro, RJ;1992.

31. Khan, M. A.; Freitas, A. C. C.; J. Heterocycl. Chem. 1983, 20, 277.

32. Freitas, A. C. C.; Barreiro, E. J.; Pereira, E. F. R.; Pereira, N. A.; Rev. Bras. Farm. 1993, 74, 57.

33. Karabatsos,G.L.; Graham, J. D.; Vane, F.M.; J. Am. Chem. Soc. 1962, 84, 753; Karabatsos,G.L.; Taller, R. A.; J. Am. Chem. Soc. 1963, 85, 3624.

34. Vinegar, R.; Truax, K.; Selph, J. L.; Voelker, F. A.; Fed. Proc. 1982, 41,2588 .

35. Whittle, B. A.; J. Pharmacol. Chemother. 1964, 22, 246.

36. Freitas, A. C. C.; Barreiro, E. J.; Pereira, E. F. R.; Pereira, N. A.; Quim Nova 1995, 18, 138

37. Silveira, I. A. B.; Paulo, L. G.; Rocha, S. O.; Miranda, A. L. P.; Freitas, A. C. C.; Barreiro, E. J.; Braz. J. Biol. Med. Res. 1991, $24,947$.

38. Silveira, I. A. F. B.; Paulo, L. G.; Miranda, A. L. P.; Barreiro, E. J.; Freitas, A. C. C.; J. Pharm. Pharmacol. 1993, 45, 646.

39. Todeschini, A. R.; Miranda, A. L. P.; da Silva, K. C. M.; Barreiro, E. J.; Parrini, S. C.; Eur. J. Med. Chem. 1998, 33, 189.

40. Balkarek, J. M. et al.; J. Biol. Chem. 1988, 263, 13937.

41. Kohl, N. E.; Emini, E. A.; Schleif, W. A.; Davis, L. J.; Heimbach, J. C.; Dixon, R. A. F.; Scolnick, E. M.; Sigal, I. S.; Proc. Natl. Acad. Sc. USA 1988, 85, 4686.

42. Asai, F.; Ito, T.; Ushiyama, S.; Arzneimittel-Forsch. 1991, 41, 506.

43. Monteiro, T. M.; Dissertação de Mestrado; UFRJ; Rio de Janeiro, RJ, 1993.

44. Barreiro, E. J.; Albuquerque, M. G.; Sant'Anna, C. M. R.; Rodrigues, C. R.; Alencastro, R. B.; Quim. Nova 1997, 29, 300.

45. Pereira, N. P.; Monteiro, T. M.; Freitas, A. C. C.; Barreiro, E. J.; Miranda, A. L. P.; Boll. Chim. Farm. 1998, 137, 82.

46. Barja-Fidalgo, C.; Fierro, I. M.; Lima, A. C. B.; da Silva, E. T.; Câmara, C. A.; Barreiro, E. J.; J. Pharm. Pharmacol. 1999, 51, 703.

47. Foye, W. O.; In Principles of Medicinal Chemistry; Foye, W. O.; Lemke, T. L.; Williams, D. A.; Eds., 4ª Edição; Williams \& Wilkins; Baltimore, 1995; p 734.

48. Patani, G.A.; LaVoie, E. J.; Chem. Rev. 1996, 96, 3147.

49. Pereira, A. S.; Violante, F. A.; Aquino Neto, F. R.; Cardoso, J. N.; Fraga, C. A. M.; Barreiro, E. J.; Anal. Lett. 1998, 31, 719.

50. Shrader, S. R.; Introductory Mass Spectrometry; Allyn \& Bacon Inc.; Boston, 1971; p 60. 
51. Albuquerque, M. G.; Rodrigues, C. R.; Alencastro, R. B.; Barreiro, E. J.; Int. J. Quantum Chem.: Quantum Biol. Symp. 1995, 22, 181.

52. a) Mahy, J.P.; Gaspard, S.; Mansuy, D.; Biochemistry 1993, 32, 4014; b) Wang, C. C.; Lai, J. E.; Chen, L. G. et al.; Bioorg. Med. Chem. 2000, 8, 2701; c) Etzenhouser, B.; Hansch, C.; Kapur, S.; Selassie, C.D.; Bioorg. Med. Chem. 2001, 9, 199; d) Rajan, P.; Vedernikova, I.; Cos, P.; Berghe, D. V.; Augustyns, K.; Haemers, A.; Bioorg. Med. Chem. 2001, 9, 215.

53. Miranda, A. L. P.; Soler, O.; Freitas, A. C. C.; Barreiro, E. J.; Can. J. Physiol. Pharmacol. 1994, 72 (Suppl. 1), 210 (P4.1.19).

54. Ormelli, C. B.; Barreiro, E. J.; Miranda, A. L. P.; XIII ${ }^{\text {th }} I U P H A R$, München, Germany, 1998.

55. Matheus, M. E.; Oliveira, L. F.; Freitas, A. C. C.; Carvalho, A. M. A. S. P.; Barreiro, E. J.; Braz. J. Biol. Med. Res. 1991, 24, 1219.

56. Martins, R. C. A.; Dissertação de Mestrado; UFRJ, Rio de Janeiro, RJ, 1995.

57. Pereira, A. L. P.; Barreiro, E. J.; Freitas, A. C. C.; Correa, C. J. C.; Gomes, L. N. L. F.; J. Liq. Chromatogr. 1991, 14, 1161.

58. Leite, L. F. C. C.; Neves, M. R.; da Silva, J. B. P.; Fraga, C. A. M.; Barreiro, E. J.; Fármaco 1999, 54, 747.

59. Leite, L. F. C. C.; Tese de Doutorado, UFRJ, Rio de Janeiro, RJ, 1996.

60. Leite, L. F. C. C.; Barreiro, E. J.; Ramos, M. N.; da Silva, J. B. P.; Galdino, S. L.; Pitta, I. R.; Spectroscopy 2000, 14, 115.

61. Figueiredo, J. M.; Câmara, C. A.; Cunha, A. C.; Ferreira, V. F.; Barreiro, E. J.; $21^{a}$ Reunião Anual da SBQ, Poços de Caldas, MG, 1998.

62. Lai, G.; Anderson, W. K.; Synth. Commun. 1997, 27, 1281.

63. Ferreira V. F.; et al.; Tetrahedron Lett. 1997, 38, 5103.

64. Barreiro, E. J.; Cunha, A. C.; Ferreira, V. F.; Miranda, A. L. P.; Fraga, C. A. M.; resultados não publicados.

65. Ribeiro, I. G.; Barreiro, E. J.; Miranda, A. L. P.; da Silva, K. C. M.; Parrini, S. C.; Fraga, C. A. M.; Eur. J. Med. Chem. 1998, 33, 225.

66. Ribeiro, I.G.; Parrini, S. C.; da Silva, K. C. M.; Miranda, A. L. P.; Fraga, C. A. M.; Barreiro, E. J.; $19^{a}$ Reunião Anual da $S B Q$, Poços de Caldas, MG, 1996.

67. Otto, H-H.; Schrmeister, T.; Chem. Rev. 1997, 97, 133

68. He, S.; Kuang, R. Z.; Venkataraman, R.; Tu, J.; Truong, T. M.; Chan, H. K.; Groutas, W. C.; Bioorg. Med. Chem. 2000, 8, 1713.

69. a) Leung, D.; Abbenante, G.; Fairlie, D. P.; J. Med. Chem. 2000, 43, 305; b) Fairlie, D. P.; Tyndall, J. D. A.; Reid, R. C.; Wong, A. K.; Abbenante, G.; March, D. R.; Bergman, D. A.; Chai, C. L. L.; Burkett, B. A.; J. Med. Chem. 2000, 43, 1271.

70. Scharfstein, J.; Ciência \& Cultura 1993, 45, 322.

71. Portoghese, P. S.; Sultana, M.; Takemori, A. E.; J. Med. Chem. 1989, 33, 1714.

72. Li, R.; Chen, X.; Gong, B.; Selzer, P. M.; Li, S.; Davidson, E.; Kurzban, G.; Miller, R. E.; Nuzum, E.; McKerrow, J. H.; Fletterick, R. J.; Gilmor, S. A.; Craik, C. S.; Kuntz, I. D.; Cohen, F. E.; Kenyon, G. I.; Bioorg. Med. Chem. 1996, 4, 1421.

73. Ifa, D. R.; Alencastro, R.B.; Barreiro, E.J. ; $20^{a}$ Reunião Anual da SBQ, Poços de Caldas, MG, 1997.

74. de Sant'Anna, C. M. R.; Alencastro, R. B.; Rodrigues, C. R.; Barreiro, G.; Barreiro, E. J.; da M. Neto, J. D.; Freitas, A. C. C.; Internat. J. Quantum Chem.: Quantum Biology Symp. 1996, 23, 111.

75. Ifa, D. R.; Rodrigues, C. R.; Alencastro, R. B.; Barreiro, E. J.; J. Mol. Struct.-Theochem. 2000, 505, 11.

76. Rodrigues, C. R.; Alencastro, R. B.; Barreiro, E. J.; $22^{a}$ Reunião Anual da $S B Q$, Poços de Caldas, MG, 1999.

77. White, E.H.; Jelinski, L. W.; Politzer, I. R.; Branchini, B. R.; Roswell, D. F.; J. Am. Chem. Soc. 1981, 103, 4231.

78. Barreiro, E. J.; Fraga, C. A. M.; Química Medicinal: As Bases Moleculares da Ação dos Fármacos; ArtMed Editora Ltda; Porto Alegre, RS, 2001, p 55.

79. Dias, L. R. S.; Dissertação de Mestrado, UFRJ, Rio de Janeiro, RJ, 1992.

80. da Silva, E. T.; Câmara, C. A.; Fraga, C. A. M.; Barreiro, E. J.; $22^{a}$ Reunião Anual da SBQ, Poços de Caldas, MG, 1999.

81. Fraga, A. G. M.; Rodrigues, C. R.; Miranda, A. L. P.; Fraga, C. A. M.; Barreiro, E. J.; Eur. J. Pharm. Sci. 2000, 11, 285.

82. Lima, P. C.; Lima, L. M.; da Silva, K. C. M.; Léda, P. H. O.; Miranda, A. L. P.; Fraga, C. A. M.; Barreiro, E. J.; Eur. J. Med. Chem. 2000, 35, 187.
83. Dias, L. R. S.; Alvim, M. J. F.; Freitas, A. C. C.; Barreiro, E. J.; Miranda, A. L. P.; Pharm. Acta Helv. 1994, 69, 163.

84. inter-alia: Woolfrey, J. R.; Rodrigues, C. R.; Alvim-Gaston, M.; Barreiro, E.J.; Cohen, F. E.; Avery, M. A.; Abstr. Pap. Am. Chem. Soc. 1999, 217, 137-COMP; Rodrigues, C. R.; Flaherty, T. M.; Springes, C.; McKerrow, J. H.; Alencastro, R. B.; Barreiro, E. J.; Cohen, F. E.; $22^{a}$ Reunião Anual da SBQ, Poços de Caldas, MG, 1999.

85. Câmara, C. A.; da Silva, E. T.; Fraga, C. A. M.; Barreiro, E. J.; Heterocycl. Commun. 1999, 5, 457.

86. Lima, P. C.; Dissertação de Mestrado; UFRJ, Rio de Janeiro, RJ,1998.

87. Santos, M. R. L.; de Carvalho, M. G.; Bráz-Filho, R.; Barreiro, E. J.; Magn. Reson. Chem. 1998, 36, 533.

88. Yamada, S.; Morizono, D.; Yamamoto, K.; Tetrahedron Lett. 1992, 33, 4329.

89. Guimarães, C. R. W.; Fraga, C. A. M.; Barreiro, E. J.; Alencastro, R. B.; $22^{a}$ Reunião Anual da SBQ, Poços de Caldas, MG, 1999.

90. de Souza, A. F.; Moreira, L. M.; Fraga, C. A. M.; Barreiro, E. J.; $22^{a}$ Reunião Anual da SBQ, Poços de Caldas, MG, 1999.

91. Léda, P. H. O.; Amarante, E. G.; Barreiro, E. J.; Miranda, A. L. M.; XIII Reunião Anual da FESBE, Caxambú, MG, 1998.

92. Santos, M. R. L.; Barreiro, E. J.; Bráz-Filho, R.; Miranda, A. L. P.; J. Braz. Chem. Soc. 1997, 8, 471.

93. Silva, E. F.; Barreiro, E. J.; J. Braz. Chem. Soc. 1993, 4, 40.

94. Lima, L. M.; Fraga, C. A. M.; Barreiro, E. J.; Pharm. Acta Helv. 1999, 73, 281 .

95. de Souza, A. F.; Lima, L. M.; Fraga, C. A. M.; Barreiro, E. J.; $21^{a}$ Reunião Anual da SBQ, Poços de Caldas, MG, 1998.

96. Figueiredo, J. M.; Camara, C. A.; Amarante, E. G.; Miranda, A. L. P.; Santos, F. M.; Rodrigues, C. R.; Fraga, C. A. M.; Barreiro, E. J.; Bioorg. Med. Chem. 2000, 8, 2243.

97. Cf. Muri, E. M. F.; Barreiro, E. J.; Fraga, C. A. M.; Synth. Commun. 1998, $28,1299$.

98. Santos, F. M.; Romeiro, N. C.; Barreiro, E. J.; $22^{a}$ Reunião Anual da SBQ, Poços de Caldas, MG, 1999.

99. Amarante, E G.; Figueiredo, J. M.; Léda, P. H. O.; Câmara, C. A.; Barreiro, E. J.; Miranda, A. L. P.; XIII Reunião Anual da FESBE, Caxambú, MG, 1998.

100. Amarante; E. G.; Lima; L. M.; Fraga, C. A. M.; Barreiro, E. J.; Miranda, A. L. P.; ALF Congress, Caxambú, MG, 2000.

101. Violante, F. A.; Câmara, C. A.; Fraga, C. A. M.; Barreiro, E. J.; $22^{a}$ Reunião Anual da SBQ, Poços de Caldas, MG, 1999.

102. Costa; L. M. M.; Brito, F. C. F.; Silva, G. A.; Barreiro, E. J.; Miranda, A. L. P.; ALF Congress, Caxambú, MG, 2000.

103. Fraga, C. A. M.; Barreiro, E. J.; Lima, L. M.; Moraes, V. L. G.; Castro, P.; $23^{a}$ Reunião Anual da SBQ, Poços de Caldas, MG, 2000; Lima, L. M.; Fraga, C. A. M.; Barreiro, E. J.; Synth. Commun. 2000, 30, 3291.

104. Figueiredo, J. M.; Câmara, C. A.; Cunha, A. C.; de Souza, M. C. B. V.; Ferreira, V. F.; Barreiro, E. J.; $22^{a}$ Reunião Anual da $S B Q$, Poços de Caldas, MG, 1999.

105. Duarte, C. de M.; de Ara;újo-Jr, J. X.; Parente, J. P.; Barreiro, E. J.;Rev. Bras. Farm. 1999, 80, 35; de Araújo-Jr., J. X.; Barreiro, E. J.; Parente, J. P.; Fraga, C. A. M.; Synth. Commun. 1999, 29, 2263.

106. Lima, L. M.; Amarante, E. G.; Miranda, A. L. P.; Fraga, C. A. M.; Barreiro, E. J.; Pharm. Pharmacol. Commun. 1999, 5, 673.

107. Silva, G. A.; Fraga, C. A. M.; Barreiro, E. J.; $22^{a}$ Reunião Anual da SBQ, Poços de Caldas, MG, 1999.

108. Szileeigye, G.; Kaszheimer, E.; Matyus, P.; Kosary, J.; Czarc, K.; Czen, G.; Huazti, Z.; Tardos, L.; Kesa, E.; Jaszlits, L.; Eur. J. Med. Chem. 1984, $19,51$.

109. Sant'Anna, C. M. R.; Alencastro R. B.; Barreiro, E. J.; J. Mol. Struct.Theochem 1999, 490, 167.

110. Braga, M. F. M.; Soler, O.; Barreiro, E. J.; Albuquerque, E. X. ; XIII Reunião Anual da FESBE, Caxambú, MG, 1998.

111. a) Zapata-Sudo, G.; Sudo, R. T.; Aguiar, M. I. S.; Lima, P. C.; Fraga, C. A. M.; Barreiro, E. J.; XIII Reunião Anual da FESBE, Caxambú, MG, 1998; b) Silva, C. L. M.; Noel, F.; Barreiro, E. J.; Fraga, C. A. M.; Lima, P. C.; XIV Reunião Anual da FESBE, Caxambú, MG, 1999.

112. Albuquerque, E. X.; Barreiro, E. J.; Sudo, R. T.; US Patent Office, Provisorial Number 60-525,352, 1999. 